\title{
Fairness analysis and compensation strategy in the Triangle of Central China driven by water-carbon- ecological footprints
}

Yizhong Chen ( $\square$ workingruning@163.com )

Hebei University of Technology

Hongwei Lu

China Academy of Sciences

Jing Li

Hebei Normal University

Youfeng Qiao

Hebei University of Technology

Pengdong Yan

Tianjin University

Lixia Ren

Shanxi Institute of Energy

Jun Xia

Wuhan University

\section{Research Article}

Keywords: Ecological compensation, Footprint family, Gini coefficient, Fairness measurement, Triangle of Central China

Posted Date: March 15th, 2021

DOI: https://doi.org/10.21203/rs.3.rs-270972/v1

License: (c) (1) This work is licensed under a Creative Commons Attribution 4.0 International License.

Read Full License 
1 Fairness analysis and compensation strategy in the Triangle of Central China

4 Yizhong Chen, ${ }^{\mathrm{a}}$ Hongwei Lu,,${ }^{\mathrm{b}}$ Jing Li,${ }^{\mathrm{c}}$ Youfeng Qiao, ${ }^{\mathrm{a}}$ Pengdong Yan, ${ }^{\mathrm{d}}$ Lixia Ren, ${ }^{\mathrm{f}}$

5 Jun Xia, e,b

$7 \quad{ }^{a}$ School of Economics and Management, Hebei University of Technology, Tianjin

8 300401, China

$9{ }^{b}$ Key Laboratory of Water Cycle and Related Land Surface Processes, Institute of

Geographic Science and Natural Resources Research, Chinese Academy of Sciences,

11 Beijing, 100101, China

${ }^{c}$ Hebei Key Laboratory of Environmental Change and Ecological Construction,

College of Resource and Environment Science, Hebei Normal University,

Shijiazhuang, 050024, China

${ }^{d}$ State Key Laboratory of Hydraulic Engineering Simulation and Safety, Tianjin

University, Tianjin 300072, China

${ }^{e}$ State Key Laboratory of Water Resources \& Hydropower Engineering Sciences,

Wuhan University, Wuhan, 430000, China

${ }^{f}$ Shanxi Institute of Energy, Shanxi, 030600, China

*Corresponding author: Tel: +86-311-80787600; Fax: +86-311-80787600;

E-mail: 1uhw@igsnrr.ac.cn (Hongwei Lu) 
24 Abstract: This study proposes water-carbon-ecological footprints to form footprint

family indicators for identifying the ecological compensation and regional development equilibrium in the Triangle of Central China (TOCC). The occupation of natural capital stock and flow consumption can be illustrated through a three-dimensional ecological footprint model, and Gini coefficient is integrated into the evaluation framework for fairness measurement from various aspects.

Quantificational ecological compensation standards can be given with concerns of ecological resource conversion efficiency and willingness to pay indicators. Results reveal that there exit rising trends in ecological and carbon footprints in the TOCC from 2000 to 2015, while its water footprint presents a fluctuating trend. A majority of average Gini coefficients exceed the warning value (i.e., 0.4) under different footprints, implying a relatively poor overall fairness of regional development. In terms of water footprint, the relatively higher compensation expenses exist in Jingmen, Xiangtan, and Yichun, while Yichang, Zhuzhou, and Fuzhou have higher received compensation values as compared with other cities. When it comes to carbon footprint, Wuhan, Loudi, and Xinyu should pay higher compensation expenses due to their overuse of biological resources. The highest amounts of compensation expense appear in Nanchang and Wuhan from the perspective of ecological footprint.

Keywords: Ecological compensation; Footprint family; Gini coefficient; Fairness measurement; Triangle of Central China 


\section{Introduction}

\subsection{Significance}

Unreasonable utilization of natural resources has led to contradictions between natural capital supply-demand in China (Kaczan, et al., 2013; Wang et al., 2018). Some environmental issues associated with climate anomalies, resources exhaustion, and water security have already played serious impacts on China's natural ecosystems and human living environments (Araujo et al., 2019), which forced the society to re-examine the traditional concept of development which focuses on economic growth.

Sustainable development has become a common concern (Shulla et al., 2020), and involves three aspects (Fedele et al., 2019): (a) further development of biodiversity and ecosystem services, (b) coordinated development of the economic, social and human well-being, and (c) economic development and environmental protection complement each other. With these concerns, China's sustainable development should maintain long-term ecological sustainability and regional equity. The environmental footprint theory simplifies the complex urbanization process to the balance of ecological supply and demand, and has become an effective method to solve the contradiction between sustainable development and ecological sustainability. However, the single footprint index cannot meet the needs of sustainable development evaluation (Kinzig et al., 2011), especially with increasingly obvious characteristics of the interaction, complexity and integrity of the earth ecosystem. With response it, the concept of footprint family (FF), such as ecological, carbon and water footprints, has 
received much attention to integrate ecological conservation and socio-economic development (Song et al., 2018; Dabkienė et al., 2020).

\subsection{Literature review}

\subsubsection{Review of combining footprint indicators}

Footprint method is a frontier method in resource-environmental pressure assessment, which originated from the term of ecological footprint and was formally introduced to the scientific community in the 1990s (Fang et al., 2014). The widely used ecological footprint is considered as one of the most important achievements in the field of sustainable development. Numerous footprint type indicators have been formulated for supplementing the ecological footprint over the past decades, such as water, carbon, energy, phosphorus, and nitrogen footprints. Recently, footprint-related researches have gradually shifted from a single footprint measurement to multiple footprints due to the complexity in resource-environmental issues. The term of FF was first advocated by Giljum et al. (2008) and Stoeglehner and Narodoslawsky (2008). Combination of ecological, water and carbon footprints are regarded as a more common model within FF approaches, which comprehensively considers the issues of land carrying capacity, water resources carrying capacity, and carbon emissions/sinks. It embodies the basic connotation of resource conservation and environmental friendliness required by the construction of ecological civilization. Numerous effects regarding FF have been made for design of the regional resource-environmental system. For example, Kissinger and Dickler (2016) used FF (i.e., ecological, land, water, and carbon footprints) for calculating beef consumption 
in the state of Israel and balancing the tradeoffs between various biophysical components. Vanham et al. (2019) applied FF for comprehensive understanding of environmental issues, policy formulation, and assessment of trade-offs between different environmental concerns. Li et al (2020) developed an integrated model for determining optimal crop planting area, irrigation water, and nitrogen fertilizer under multiple uncertainties, where water-carbon- energy-ecological footprints were analyzed to jointly evaluate the resource re-allocation.

\subsubsection{Review of ecological compensation}

There are certain differences in economic development and resource utilization in different regions, resulting in certain unfairness in the use of ecological resources and environmental protection between regions. In response to such differences, ecological compensation is an important way to promote regional coordinated development (Wang et al., 2020). Recently, international exploratory studies have been made to forest ecological compensation in China (Jiang et al., 2016). For example, Fan and Chen (2019) established a comprehensive evaluation framework for identifying the spatial characteristics of land uses and ecological compensation from 2000 to 2015 in Sichuan Province, China. Jiang et al. (2019) advanced a stochastic differential game model for determining transboundary pollution control options between a compensating and compensated region. Findings can help decision makers identify relative ecological and economic thresholds for deploying ecological footprint contracts across China. Guo et al. (2020) centered on the influencing factors of watershed ecological compensation system in the Eastern Route of South-to-North 
Water Transfer Project. Results revealed that the upstream governments would get about $78 \%$ of ecological benefits owing to the implementation of watershed ecological compensation system. Yang et al. (2020) focused on ecological compensation standards of national scenic spots in Taibai Mountain of China based on ecological footprint method, which can reduce the touristic ecological footprint and improve implementation of the compensation mechanism.

\subsubsection{Review of regional fairness analyses}

With increasingly close relationship between economic development and biological resources consumption, it is particularly critical to maintain the fairness between their development (Figueras and Duro, 2015). There are many efforts undertaken for the fairness analyses. For example, Chen et al. (2017) used Gini and deviation indexes for evaluating differences in the per capita consumption of fossil energy across 30 Chinese provinces from 1997 to 2013. Results revealed that the Gini rate of Chinese inter-provincial fossil energy consumption was less than 0.3. Dai et al. (2018) developed a Gini-coefficient based stochastic optimization model for supporting water resources allocation at a watershed scale in Lake Dianchi watershed, China. Results provided a proper tradeoff between system benefit and water allocation equity. Shu and Xiong (2018) constructed a non-grouped Gini index for identifying regionally balanced development of economy and environment in China. Yang and Fan (2019) applied energy ecological footprint to analyze the spatial-temporal differences and fairness of the Silk Road Economic Belt. Results indicated that its economic contribution and energy ecological support Gini coefficients ranged from 
$[0.19,0.25]$ and $[0.30,0.35]$, respectively.

\subsection{Novelty and contribution}

In spite of numerous effects undertaken for ecological compensation assessment, some issues have not been substantially resolved, such as lack of institutional standardization and compensation standards. It is thus necessary to propose a novel method for determining compensation standard (He et al., 2018), especially in China with a top-down administrative management system (Wang and Wall, 2016). In response to this concern, a comprehensive ecological compensation framework based on FF analysis is regarded as one of the most practical manner. The aim of FF is to track natural resource occupancy, greenhouse gas emissions, and water resources consumption generated by human activities from the biosphere, atmosphere and hydrosphere (Galli et al. 2013). Compared with the traditional compensation methods, FF method can effectively avoid the influence of subjective factors, which can objectively determine subject and object of ecological compensation and its specific amounts. Moreover, there are considerable differences in the spatial distribution of China's biological resources consumption within different land-use types, and the resulting ecological environment problems are unresolved (Xue et al., 2014). With consideration of the asymmetry of economic growth, it is significantly desired to judge fairness between FF and the regional economic development (White, 2017).

Gini coefficient is an indicator tool for quantitative determination of balances based on the Lorentz curve, which has been widely used to evaluate the regional balanced development (Teng et al., 2011; Shu and Xiong, 2018). 


\subsection{Objective and paper organization}

The objective of this study targets to develop a comprehensive ecological compensation model driven by water-carbon-ecological footprints. Gini coefficient will be used for measuring fairness of the regional development. The developed model will then be applied to the Triangle of Central China (TOCC). Some critical questions will be answered, such as footprints deficit or surplus, regional development equilibrium, and compensation strategies. Findings will provide a robust decisionmaking reference for the sustainable development in the TOCC. The structure of this paper is presented as follows: Section 2 shows the detailed materials and methods; Section 3 displays the solutions in association with water-carbon-ecological footprints, their corresponding compensation, and differences in regional development; Section 4 presents discussion, and Section 5 shows conclusions.

\section{Materials and methods}

\subsection{Problems statement}

The TOCC $\left(108^{\circ} 21^{\prime} \mathrm{E} \sim 118^{\circ} 28^{\prime} \mathrm{E}\right.$ and $\left.20^{\circ} 09^{\prime} \mathrm{N} \sim 33^{\circ} 20^{\prime} \mathrm{N}\right)$ consists of Hubei, Hunan, and Jiangxi Provinces, which has an area of $32.61 \times 10^{4} \mathrm{~km}^{2}$ with a center of Wuhan. The TOCC mostly includes the four city groups, i.e., Poyang Lake City Group (PLCG), Chang-Zhu-Tan City Group (CZTCG), Wuhan Metropolitan Area (WMA), and Xiang-Jing-Yi City Group (XJYCG) (Figure 1). It should be specially mentioned that WMA and XJYCG are integrated as one urban agglomeration named as WMA\& XJYCG. Table 1 gives the specific city division. The TOCC is an important part of the Yangtze River Economic Belt, China, and has four biodiversity 
177 protection ecological function zones with important ecological service functions.

178 Figure 2 shows the spatial distribution of per unit of GDP and population in the

179 TOCC across Yangtze River Economic Belt. In 2017, its total population reached 125

180 million with a GDP of 7.90 trillion RMB $¥$ (ranking fifth in China’s urban

181 agglomeration). The TOCC has created $9.6 \%$ of the total economic output on basis of

$1823.4 \%$ and $9.0 \%$ of China's land area and population, respectively. In recent years, the

183 excessive concentration of heavy chemical industries and extensive resource

184 utilization resulted in huge amounts of water resources consumption and sewage

185 discharge. Generally, the pressure of ecological environment and problems of

186 ecological security in the TOCC during economic development are more prominent.

\subsection{Footprint family indicators}

(a) Water footprint model: water footprint refers to the area of water resources

characteristics.

$195 T W F=M \cdot W F=M \cdot b b_{w} \cdot\left(B / h_{w}\right)$ 
$\left(\mathrm{hm}^{2}\right) ; W F$ denotes per capita water footprint ( $\left.\mathrm{hm}^{2} / \mathrm{cap}\right) ; W C$ denotes per capita water carrying capacity ( $\mathrm{hm}^{2} /$ cap); $W D$ denotes water deficit; $b b_{w}$ represents the global equilibrium factor of water resources; $h_{w}$ represents the global average water production $\left(\mathrm{m}^{3} / \mathrm{hm}^{2}\right) ; B$ represents per capita water consumption $\left(\mathrm{m}^{3} / \mathrm{cap}\right) ; c c$ represents water resources production factor that is a ratio of the average output of regional water resources to the average output of global water resources; $D$ represents regional water resources availability.

(b) Carbon footprint model: the coefficient method is used for determining the amounts of carbon absorption $(C A)$ and carbon emissions $(C E)$, as follows:

$$
C A=\sum A R_{i} \cdot s S_{i}
$$

$$
C E=\sum x x_{j} \cdot y y_{j} \cdot z z_{j}
$$

$$
N C E=C E-C A=\sum x x_{j} \cdot y y_{j} \cdot z z_{j}-\sum A R_{i} \cdot s S_{i}
$$

where $A R_{i}$ denotes the area of $i$ th land type $\left(\mathrm{hm}^{2}\right)$; ssi denotes the carbon absorption coefficient $\left(\mathrm{tC} / \mathrm{hm}^{2}\right) ; x x_{j}$ denotes the amount of energy consumption $(\mathrm{t}) ; y y_{j}$ denotes standard coal conversion coefficient; $z z_{j}$ denotes the emission coefficient of $i$ th energy $(\mathrm{tC} / \mathrm{t}) ; N C E$ denotes the amount of net carbon emissions $(\mathrm{tC})$. In addition, the carbon carrying capacity $(C C)$ and carbon footprint $(C F)$ can be stated as follows:

$$
C F=\frac{N C E}{N} \cdot\left(\frac{R_{f}}{N S P_{f}}+\frac{R_{g}}{N S P_{g}}+\frac{R_{a}}{N S P_{a}}\right)
$$

$$
C C=\frac{C A}{N} \cdot\left(\frac{R_{f}}{N S P_{f}}+\frac{R_{g}}{N S P_{g}}+\frac{R_{a}}{N S P_{a}}\right)
$$

$$
C D=C F-C C
$$

where $N S P_{f}, N S P_{g}$, and $N S P_{a}$ denote the carbon sequestration capacity of forest, grassland, and cultivated land $\left(\mathrm{tC} / \mathrm{hm}^{2}\right)$, respectively; $R_{f}, R_{g}$ and $R_{a}$ denote the 
proportions of carbon sequestration in terms of forest, grassland, and cultivated land, respectively; $N$ is the total population; $C D$ denotes carbon deficit.

(c) Ecological footprint model: the traditional ecological footprint $(E F)$ model is presented as follow, where $E C$ denotes the total regional ecological capacity that refers to the total area of bio productive land for providing human survival and development $\left(\mathrm{hm}^{2}\right) ; i$ refers to a certain natural capital category; $n$ refers to the total number of natural capital categories; $j$ refers to different land-use type; $r_{j}$ refers to equilibrium factor; $y_{j}$ refers to yield factor; $p_{j}$ and $c_{j}$ refers to average production capacity and consumption level of a certain natural capital category, respectively; $a_{i}$ refers to land area converted by a certain natural capital category $\left(\mathrm{hm}^{2}\right) ; A_{j}$ denotes the actual land use area $\left(\mathrm{hm}^{2}\right) ; N$ denotes the population; $e f_{e}$ and $e c_{e}$ denote the ecological footprint and carrying capacity ( $\left.\mathrm{hm}^{2} / \mathrm{cap}\right)$, respectively; $E D$ denotes ecological deficit.

$$
E F=N \times e f_{e}=N \times \sum_{i=1}^{n}\left(\mathrm{r}_{j} \times \mathrm{a}_{i}\right)=N \times \sum_{i=1}^{n} r_{j}\left(\frac{c_{i}}{p_{i}}\right)
$$

$$
E C=N \times e c_{e}=N \times \sum_{j=1}^{6} A_{j} \times r_{j} \times y_{j}(\mathrm{j}=1,2, \cdots 6)
$$

$$
E D=E F-E C
$$

The traditional ecological footprint model focuses on the measurement of flow capital, while ignoring stock capital that plays a critical role in regional ecosystem balance. In response to such concern, the three-dimensional ecological footprint $\left(E F_{3 D}\right)$ model introduces two indexes (footprint depth and breadth) to represent the extent to which humans consume natural capital stock and occupy natural capital flows. The formula is as follows: 
243 where $E F_{\text {depth }}$ is ecological footprint depth that refers to the multiples of land area theoretically required to maintain the existing level of resource consumption in the region. $E F_{\text {depth }}$ reflects the consumption of natural capital stock that exceeds the ecological carrying capacity. $E F_{\text {size }}$ is ecological footprint size that refers to the area occupying biologically productive land within the region's carrying capacity. It reflects the level of natural capital flow occupied by human beings (Fang, 2015).

$E F_{\text {depth }}=1+\frac{E D}{E C}=1+\frac{\sum_{i=1}^{n} \max \left[E F_{i}-E C_{i,}, 0\right]}{\sum_{i=1}^{n} E C_{i}}$

$E F_{\text {size }}=\sum_{i=1}^{n} \min \left\{E F_{i}, E C_{i}\right\}$

where $E D$ is the total ecological deficit; $E C$ is the total ecological carrying capacity.

When $E F_{\text {depth }}$ equals to 1, it means that flow capital can just meet the demand for resource consumption; when $E F_{\text {depth }}$ is greater than 1, it means that flow capital cannot meet consumption demand, and stock capital must be consumed.

\subsection{Regional fairness analysis}

The traditional Gini coefficient $(G)$ is employed for evaluating regional fairness

of the income distribution of residents (Eliazar and Cohen, 2014). It should be

specially mentioned that the basis of interval division is consistent with income

$262 \quad G=1-\sum_{i-1}^{n}\left(x_{i}-x_{i-1}\right) \cdot\left(y_{i}+y_{i-1}\right)$ 
where $x_{\mathrm{i}}$ represents the cumulative percentage of the equity evaluation indicators of city $i$ after their ranking; $y_{i}$ is the cumulative percentage of water-carbon-ecological footprints of city $i$; when $i=1, x_{\mathrm{i}}-1$ and $y_{i}-1$ equal to zero. The values of Gini coefficient range from 0 to 1 . A high Gini coefficient corresponds to a low fairness level; a low Gini coefficient leads to a high fairness level.

\subsection{Ecological compensation model}

The amount of ecological compensation deserved in each area can be determined according to FF approach, during which the ecological resource conversion efficiency

271 and willingness to pay indicators are considered.

\section{(a) Ecological resource conversion efficiency}

$273 \quad U_{R}=\frac{e f_{R}}{p_{R}}$

274 where the subscript of $R$ denotes a specific city; $U$ represents water/carbon/ecological

275 footprint per ten thousand-yuan GDP; ef is per capita water/carbon/ecological

276 footprint; $p$ denotes per capita GDP.

\section{(b) Willingness to pay indicator}

$278 \quad W_{R}=\frac{p_{R} \times I_{R}}{\bar{p}}$

$279 \quad l_{R}=\frac{1}{1+e^{-t}}, t=\frac{I n_{R}}{I n}$

$280 \quad \operatorname{In}=\frac{A \times m+B \times n}{m+n}$

281 where $W$ denotes the indicator of willingness to pay; $l$ denotes a city's development

282 stage coefficient; $\bar{p}$ denotes a province's per capita GDP; In denotes a city's per 
capita income; $\overline{l n}$ denotes a province's per capita income; $A$ is the urban per capita disposable income; $m$ is the urban population; $B$ is rural per capita net income; $n$ is the rural population.

$$
\beta_{R}=\frac{E C_{R}}{\sum E C}
$$

$V_{R}=M \times \beta_{R}$

where $\beta$ is the supply coefficient of ecological services; $E C$ is water/carbon/ecological carrying capacity; $V$ is the amount of money arising from supply of ecological services; $M$ is the total amount of ecological services in each province, which is represented by regional investment in pollution control in this study.

\section{(d) Ecological service consumption coefficient}

$\operatorname{Rec}_{R}=\frac{U_{R} \times W_{R}}{\sigma \times W}$

$\alpha_{R}=\frac{E F_{R} \times R e c_{R}}{\sum_{R=1}^{\mathrm{n}}\left(E F_{R} \times \operatorname{Rec}_{R}\right)}$

$$
F_{R}=M \times \alpha_{R}
$$

297 where $R e c$ is the comprehensive correction coefficient; $\bar{U}$ is average ecological

298 footprint of ten thousand-yuan GDP in a province; $\bar{W}$ is average willingness to pay in a province; $\alpha$ is ecological service consumption coefficient; $F$ is ecological service consumption values.

\section{(e) Amount of ecological compensation}


means that the city's ecological compensation amount is a net inflow; otherwise,

305 it is a net outflow.

\subsection{Data sources}

In this study, the social-economic data are mostly obtained from Hunan, Jiangxi and Hubei Provincial Statistical Yearbook from 2000 to 2015. This study uses ArcGIS with spatial resolution of $1 \mathrm{~km} \times 1 \mathrm{~km}$ to extract land classification that is divided into six categories (i.e., cultivated land, grassland, forest land, water land, construction land, and fossil fuel land). The data associated with biological resource consumption and energy consumption are collected for calculating different footprints. Among of them, biological resources are divided into agricultural, animal, forest and aquatic products. Energy resources are divided into industrial consumption of energy and to $2239 \mathrm{~mm}$, and the altitude is between 20 and $3105 \mathrm{~m}$. Cultivated land, forest land, and water have a major position of the regional land uses (Figure 3).

\section{Results analysis}

\subsection{Spatial-temporal dynamic analysis of water-carbon-ecological footprints}

The general ecological and carbon footprints of different urban agglomerations 
footprint in the WMA\&XJYCG increases from $0.302 \mathrm{hm}^{2} /$ cap in 2000 to 0.593 $\mathrm{hm}^{2} /$ cap in 2015; that in the PLCG increases from $0.267 \mathrm{hm}^{2} /$ cap in 2000 to 0.662 $\mathrm{hm}^{2} /$ cap in 2015 . In terms of ecological footprint, its value raises from $2.087 \mathrm{hm}^{2} / \mathrm{cap}$ in 2000 to $4.360 \mathrm{hm}^{2} / \mathrm{cap}$ in 2015 , with an annual growth rate of $5.0 \%$. In comparison, water footprint in all urban agglomerations shows a fluctuating trend. Figure 5 presents the detailed solutions of water footprint in different urban agglomerations. Results show that its average values range from $0.606 \mathrm{hm}^{2} / \mathrm{cap}$ (Yichang, W5) to $1.435 \mathrm{hm}^{2} /$ cap (Jingmen, W6), from $0.632 \mathrm{hm}^{2} /$ cap (Hengyang, C7) to $1.120 \mathrm{hm}^{2} /$ cap (Xiangtan, C3), and from $0.628 \mathrm{hm}^{2} / \mathrm{cap}$ (Jingdezhen, P3) to $1.283 \mathrm{hm}^{2} / \mathrm{cap}$ (Yingtan, P4) in the WMA\&XJYCG, CZTCG, and PLCG, respectively. The corresponding average water carrying capacity ranges from $0.446 \mathrm{hm}^{2} /$ cap (Xiaogan, W8) to 4.949 $\mathrm{hm}^{2} /$ cap (Xianning, W10), from $2.286 \mathrm{hm}^{2} /$ cap (Xiangtan, C3) to $5.530 \mathrm{hm}^{2} / \mathrm{cap}$ (Zhuzhou, C2), and from $4.308 \mathrm{hm}^{2} /$ cap (Jingdezhen, P3) to $13.151 \mathrm{hm}^{2} / \mathrm{cap}$ (Fuzhou, population and economics, especially in Wuhan and Xiaogan of the WMA\&XJYCG. P9). As shown in Figure 6, high water carrying capacity mostly appears in the southeast of TOCC, especially in Fuzhou and Yingtan of the PLCG. By contrary, low water carrying capacity exists in the northwest of TOCC due to its highly intensity of

Figure 7 illustrates the changes of carbon footprint in different urban 
majority of their carbon deficit greater than zero, especially in the WMA\&XJYCG

349 and PLCG with average values of 0.4248 and $0.4624 \mathrm{hm}^{2} /$ cap. Specifically, the

350 average carbon footprints in the WMA\&XJYCG, CZTCG, and PLCG reach 0.4411,

3510.4338 , and $0.4919 \mathrm{hm}^{2} / \mathrm{cap}$, respectively. The highest carbon footprints of these three

352 urban agglomerations exist in Ezhou, Loudi, and Xinyu with average values of 1.181,

3531.330 , and $1.431 \mathrm{hm}^{2} /$ cap, respectively. This is mainly due to the large consumption

354 of coal in these areas. When it comes to the average carbon carrying capacity in the

355 three urban agglomerations, its values reach $0.0163,0.0189$, and $0.0337 \mathrm{hm}^{2} / \mathrm{cap}$,

356 respectively. About $94.2 \%$ of the total carbon absorption is contributed by forest land,

357 followed by water land (4.02\%). Ji'an and Yichang have a high contribution rate to the

358 total carbon carrying capacity, with areas of $0.2736 \times 10^{6} \mathrm{hm}^{2}$ and $0.2684 \times 10^{6} \mathrm{hm}^{2}$,

359 respectively. Such a circumstance is mostly due to these two cities with wide area of

360 forest land and crops, and thus resulting in a strong carbon sequestration capacity.

361 Figure 8 displays the spatial-temporal dynamic variations of carbon footprint and

362 carbon carrying capacity. In the southeast of TOCC, carbon carrying capacity is

363 relatively high, while low carbon carrying capacity is mainly distributed in the

364 northeast and southwest areas. A high-level economic development is normally

365 accompanied by a large carbon footprint (e.g., Wuhan); on the contrary, the

366 urbanization level of Xiantao and Tianmen is relatively slow with a low amount of

367 coal consumption, resulting in their relatively low carbon footprints. 
WMA\&XJYCG increases from $2.435 \mathrm{hm}^{2} /$ cap in 2000 to $5.465 \mathrm{hm}^{2} /$ cap in 2015 with an annual growth rate of $5.55 \%$; that in the CZTCG raises from $2.231 \mathrm{hm}^{2} /$ cap in 2000 to $4.126 \mathrm{hm}^{2} /$ cap in 2015 with an annual growth rate of $4.52 \%$; that in the PLCG increases from $1.416 \mathrm{hm}^{2} /$ cap in 2000 to $3.245 \mathrm{hm}^{2} /$ cap in 2015 with an annual growth rate of 5.34\%. From 2000 to 2015 , the relationship of per capita ecological footprint under different land-use types in TOCC is: grassland $>$ cultivated land $>$ fossil fuel land $>$ forest land $>$ water area $>$ built-up land. The per capita ecological footprint from grassland and cultivated land accounts for about $82.58 \%$ of the overall, and that from fossil fuel land is $15.71 \%$ of the overall. In comparison, the ecological carrying capacity levels only reach $0.3301,0.3009$, and $0.4229 \mathrm{hm}^{2} /$ cap in the WMA\&XJYCG, CZTCG, and PLCG, with ecological deficits of $3.6098,3.2546$, and $2.1334 \mathrm{hm}^{2} / \mathrm{cap}$, respectively. From 2000 to 2015, among the various land types in the TOCC, the ecological carrying capacity of water area and construction land has an increased trend, while that in other land types declines. Compared with 2000, the ecological carrying capacity of cultivated land and forest land decrease by $0.31 \mathrm{hm}^{2} /$ cap in 2015 .

In general, the ecological footprint in TOCC shows an increased trend over the periods from 2000 to 2015. Ezhou has the largest contribution to the growth of ecological footprint of urban agglomerations, which is due to its high-intensity population and energy consumption (Figure 10). 

different urban agglomerations present unimodal patterns (Figure 11), implying that the water-carbon-ecological performances in TOCC are not reach the extent of becoming divided. The ecological, water, and carbon footprints in the

WMA\&XJYCG mostly lie in the intervals of $[2,4],[0.5,1.5]$, and $[0,0.5] \mathrm{hm}^{2} / \mathrm{cap}$; $0.5] \mathrm{hm}^{2} /$ cap, respectively.

\subsection{Regional fairness analysis based on water-carbon-ecological footprint} matching degree: $G<0.2$ for absolute match; $0.2 \leq G<0.3$ for comparative match; 0.3

$411 \leq G<0.4$ for relative match; $0.4 \leq G<0.5$ for general mismatch; $0.5 \leq G<0.6$ for comparative mismatch, and $G \geq 0.6$ for serious mismatch. population Gini coefficient has a slight change over the periods from 2000 to 2015, 415 with an annual average of 0.373 basically below the warning value. Its average GDP 
resource footprint and GDP growth match poorly. In terms of water resources Gini coefficient, its average value is 0.442 from 2000 to 2015 , with a majority of water resources Gini coefficient at a general mismatch state except for the periods of 2006 and 2014. In 2012, the water resources Gini coefficient significantly exceeds the warning value, reaching 0.553 with a comparative mismatch state. The above variations are mostly due to the large change in precipitation yet slight change in water footprint in these years, resulting in the mismatch between water resources and water footprint. In general, the relationship among population distribution, economic development, water resources and water footprint are not harmonious due to the comprehensive Gini coefficient reaching 0.421. In terms of carbon footprint (Figure $12 b$ and Figure $13 \mathrm{~d}-\mathrm{f}$ ), there are increased tends in its population, GDP, and water resources Gini coefficients during the periods from 2000 to 2015 . Its population and GDP Gini coefficients from 2000 to 2010 are below the warning value of 0.4 and at a relative match state. However, its population Gini coefficient from 2011 to 2015 exceeds the warning value, with a general mismatch state. Most of the water resources Gini coefficients lie in the states of general mismatch and comparative mismatch. Its comprehensive Gini coefficient increases from 0.2573 in 2000 to 0.4423 in 2015. From the perspective of ecological footprint (Figure 12c and Figure $13 \mathrm{~g}$-i), its population, GDP, and water resources Gini coefficients change slightly from 2000 to 2015, ranging from 0.365 to 0.444 (with an average value of 0.395 ), from 0.415 to 0.506 (with an average value of 0.457 ), and from 0.472 to 0.593 (with an average value of 0.516 ), respectively. The average value of comprehensive Gini coefficient is 
0.456, which is in the state of general mismatch. It is worth noting that both GDP and water resources Gini coefficients are above the warning line, while population Gini coefficient is higher than the warning value only after 2011.

Place Figure 12 and Figure 13 here

\subsection{Spatial-temporal dynamic analysis of compensation strategies}

According to the concerns of ecological service supply and consumption, the amount of ecological compensation among different cities can be determined. Results indicate significant differences in ecological service consumption values of different urban agglomerations. For example, the average ecological service consumption values in the WMA\&XJYCG increase from $6556.76 \times 10^{4} \mathrm{RMB} ¥$ in 2000 to $12149.54 \times 10^{4} \mathrm{RMB} ¥$ in 2015 ; that in the CZTCG raise from $19574.50 \times 10^{4} \mathrm{RMB}$ $¥$ in 2000 to $400000 \times 10^{4} \mathrm{RMB} ¥$ in 2015 ; that in the PLCG increase from $15154.50 \times 10^{4} \mathrm{RMB} ¥$ in 2000 to $360000 \times 10^{4} \mathrm{RMB} ¥$ in 2015 . Specifically, about $29.78 \%$ of total service consumption values of water resources within the WMA\&XJYCG exist in Wuhan and Jingzhou with values of $21754.61 \times 10^{4}$ and $26541.14 \times 10^{4} \mathrm{RMB} ¥$, respectively (Figure 14 ). The relatively higher service consumption values of water resources in the CZTCG appear in Changsha and Changde with values of $225301.02 \times 10^{4}$ and $190999.06 \times 10^{4} \mathrm{RMB} ¥$, accounting for approximately $37.82 \%$ of the total value in the CZTCG. Nearly $42.98 \%$ of total service consumption values of water resources in the PLCG come from Yichun and 
Nanchang with values of $336322.06 \times 10^{4}$ and $187155.96 \times 10^{4} \mathrm{RMB} ¥$, respectively. In terms of carbon concern, its relatively higher service consumption values in the WMA\&XJYCG exist in Jingmen and Yichang with values of $32374.34 \times 10^{4}$ and $38309.34 \times 10^{4} \mathrm{RMB} ¥$, which contribute approximately $43.58 \%$ to the total values. The carbon service consumption values in Loudi and Yueyang reach $617613.70 \times 10^{4}$ and $186529.42 \times 10^{4} \mathrm{RMB} ¥$, accounting for about $73.07 \%$ of the total values in the CZTCG. Above 55\% of total carbon service consumption values in the PLCG are contributed by Xinyu and Jiujiang with values of $405088.21 \times 10^{4}$ and $316757.95 \times 10^{4}$ RMB $¥$, respectively.

Place Figure 14 here perspective of water-carbon-ecological footprints are illustrated in Figure 15. From aspect of water footprint, Wuhan and Jingmen in the WMA\&XJYCG pay higher compensation expenses with average values of $-11093.30 \times 10^{4}$ and $-20339.23 \times 10^{4}$ RMB $¥$, respectively, while Yichang has a relatively higher amount of received compensation with a value of $20339.23 \times 10^{4} \mathrm{RMB} ¥$. In terms of the per capita level, its higher compensation expenses appear in Ezhou and Tianmen with values of -58.78 and $-23.49 \mathrm{RMB} ¥$, while 82.41 and $50.85 \mathrm{RMB} ¥$ of compensation can be received by Xianning and Yichang. In the CZTCG, its higher compensation expenses exist in Changsha and Xiangtan with values of $-64602.40 \times 10^{4}$ and $-69140.82 \times 10^{4} \mathrm{RMB} ¥$, 
respectively; their corresponding per capita compensation values reach -93.59 and $-244.48 \mathrm{RMB} ¥$. The higher amount of received compensation in the CZTCG exist in Yiyang and Zhuzhou with values of 61131.41 and 57344.15 RMB $¥$. Loudi has less population compared with Yiyang, which results in a higher per capita received compensation value (146.77 RMB ¥) in Loudi, followed by Zhuzhou (139.13 RMB ¥). As for the PLCG, Xinyu and Yichun have relatively higher compensation expenses over the periods from 2000 to 2015 , reaching -34679.24 and $-137876.25 \mathrm{RMB} ¥$, respectively. Their resulting per capital compensation expenses are -302.10 and $-252.58 \mathrm{RMB} ¥ / \mathrm{cap}$. Its higher received compensation value exists in Fuzhou with values of $118267.82 \times 10^{4} \mathrm{RMB} ¥$ and $260.26 \mathrm{RMB} ¥ /$ cap. When viewed from time dimension, the overall per capital compensation expenses in the WMA\&XJYCG increase from $-1.35 \mathrm{RMB} ¥ /$ cap in 2000 to $-8.58 \mathrm{RMB} ¥ /$ cap in 2015 . The received compensation in the CZTCG raises from $0.19 \mathrm{RMB} ¥ /$ cap in 2000 to $0.88 \mathrm{RMB} ¥ /$ cap in 2015. The compensation strategy in the PLCG is at a payment status, while it changes to an obtaining status.

In the view of carbon footprint, its higher compensation expenses in the WMA\&XJYCG exist in Wuhan (i.e., average value of $-24136.4 \times 10^{4} \mathrm{RMB} ¥$ ) and Ezhou (i.e., average value of $-20207.9 \times 10^{4}$ RMB $¥$ ), while its most of received compensation appear in Huanggang (i.e., average value of $24103.2 \times 10^{4} \mathrm{RMB} ¥$ ) and Xiangfan (i.e., average value of $18218.5 \times 10^{4} \mathrm{RMB} ¥$ ). Its higher per capita compensation expenses can be seen in Ezhou and Huangshi with values of -187.7 and -58.1 RMB ¥/cap, while Xianning and Huanggang have higher received compensation 
with averages of 49.1 and 33.6 RMB $¥ /$ cap, respectively. In the CZTCG, Loudi and Xiangtan have greater compensation expenses with averages of $-500533.5 \times 10^{4}$ and $-46297.1 \times 10^{4} \mathrm{RMB} ¥$, respectively. Their corresponding per capital compensation expenses amount to -1274.5 and -163.7 RMB $¥ /$ cap. In comparison, Changde and Hengyang have some carbon-emission surpluses with higher received compensation of $148313.4 \times 10^{4}$ and $151091.5 \times 10^{4} \mathrm{RMB} ¥$, respectively. When it comes to the PLCG, its relatively higher compensation expenses can be found in Xinyu and Pingxiang with averages of $-377589.2 \times 10^{4}$ and $-167642.5 \times 10^{4} \mathrm{RMB} ¥$, respectively, while its greater received compensation can be observed in Shangrao (i.e., average value of $205932.1 \times 10^{4}$ RMB $\left.¥\right)$ and Ji'an (i.e., average value of $229428.3 \times 10^{4}$ RMB $¥$ ). From the perspective of per capita level, Fuzhou with low population has relatively higher received compensation with a value of 501.6 RMB ¥/cap compared with Shangrao. Generally, the amount of compensation expenses increases from -5.5 RMB ¥/cap in 2000 to $-27.3 \mathrm{RMB} ¥ /$ cap in 2015 , from $-11.8 \mathrm{RMB} ¥ /$ cap in 2000 to $-216.7 \mathrm{RMB}$ $¥ /$ cap in 2015 , and from $-30.9 \mathrm{RMB} ¥ / \mathrm{cap}$ in 2000 to $-798.2 \mathrm{RMB} ¥ /$ cap in 2015 in the WMA\&XJYCG, CZTCG, and PLCG, respectively.

In terms of ecological footprint, the highest amount of compensation expense of the PLCG appears in Nanchang with an average value of $-142883.8 \times 10^{4} \mathrm{RMB} ¥$; in comparison, the highest amount of received compensation exists in Shangrao (i.e., $\left.171102.4 \times 10^{4} \mathrm{RMB} ¥\right)$. In the WMA\&XJYCG, Wuhan pays the greatest amount of compensation expense (i.e., $\left.-13951.6 \times 10^{4} \mathrm{RMB} ¥\right)$, while Yichang receives about $16496.3 \times 10^{4} \mathrm{RMB} ¥$ of average received compensation from 2000 t0 2015. From the 

per capita level, the highest compensation expense and received compensation exits in Xinyu and Shangrao with averages of -476.7 and 258.6 RMB ¥/cap. When it comes to the CZTCG, Yueyang (-125.1 RMB ¥/cap) and Zhuzhou (160.4 RMB ¥/cap) have the highest compensation expense and received compensation over the periods from 2000 to 2015. In the WMA\&XJYCG, its greatest amount of compensation expense appears in Ezhou (-84.3 RMB ¥/cap) and Yichang (41.2 RMB ¥/cap), respectively. In general, the cities that pay for ecological compensation are mostly concentrated in the central of each urban agglomeration, with rapid economic development and high GDP. The amount of ecological resources consumed by economic development exceeds the regional ecological carrying capacity, and the ecological resources of other regions need to be occupied and compensated. Due to geographic location and terrain ecological carrying capacity, which can provide ecological services to other cities and

540 obtain corresponding ecological compensation.

\section{Discussion}

Two major reasons are presented for driving this study. Firstly, a general

546 footprint evaluation framework frequently targets at ecological concern. However, the

547 footprint induced by economic development and human activities in the urban agglomerations is not limited by only one. This study integrates water, carbon, and 
ecological footprints into a comprehensive compensation evaluation framework for

550 illustrating the change track of environmental impact in the TOCC. Secondly, most of

551 the previous studies can hardly set reasonable standards and measure regional fairness

552 caused by the differences in biological resources consumption. With these concerns,

553 this study proposed a footprint family-based compensation approach, which can

554 effectively avoid the influence of subjective factors. The Gini coefficient is then

555 merged into the footprint family evaluation framework and is used to identify the

556 fairness among different cities and urban agglomerations. However, two concerns

557 need to be paid attention in future studies. One is that the developed model did not

558 consider multiple uncertainties normally expressed as interval, fuzzy, and stochastic

559 parameters into the general framework. The introduction of these uncertainties

560 probably leads to significant differences in water-carbon-ecological footprints and

561 compensation amounts. The other one is to apply reliability-resilience-vulnerability

562 indexes to the footprint family problems (Lu et al., 2019), which is beneficial to

563 comprehensively evaluate regional environment safety and to establish management

564 policies for joint long-term control of RRV at the regional scale (Asefa et al., 2014).

\section{5. Conclusions}

In this study, a footprint family-based compensation model is developed for

567 descripting the spatial-temporal dynamics in water-carbon-ecological footprints and

568 compensation strategies at the city scale across the TOCC, China. This is the first

569 attempt to improved footprint family-based compensation model for identifying

regional environment pressure, service providers and beneficiaries, and equity in 
urban development. The conclusions can be summarized as follows: (a) during the periods from 2000 to 2015 , ecological and carbon footprints in the TOCC keep rising, while water footprint has a fluctuating trend. In general, most of the ecological, water, and carbon footprints in the WMA\&XJYCG lie in the intervals of $[2,4],[0.5,1.5]$, and $[0,0.5] \mathrm{hm}^{2} /$ cap, respectively; those in the CZTCG appear in the intervals of [2, 4], $[0.8,1.0]$, and $[0.2,0.4] \mathrm{hm}^{2} /$ cap, respectively; those in the PLCG exist in the intervals of [1, 2], $[0.6,0.8]$, and $[0,0.5] \mathrm{hm}^{2} /$ cap, respectively; (b) in the view of water footprint, its average population, GDP, and water resources Gini coefficients reach $0.373,0.450$, and 0.442 from 2000 to 2015 , respectively. In terms of carbon footprint, these are increased tends in its population, GDP, and water resources Gini coefficients during the periods from 2000 to 2015 , especially its population and water resources Gini coefficients exceeding the warning value. From the perspective of ecological footprint, its population, GDP, and water resources Gini coefficients vary slightly with averages of $0.395,0.457$, and 0.516 , which should be paid more attention due to most of them higher than 0.40; (c) When considering water footprint, Wuhan, Jingmen Changsha, Xiangtan, Xinyu and Yichun have relatively higher compensation expenses; in comparison, Yichang, Yiyang, Zhuzhou, and Fuzhou have relatively higher received compensation values. In terms of carbon footprint, Wuhan, Ezhou, Loudi, Xiangtan, Xinyu and Pingxiang should pay higher compensation expenses due to their overuse of biological resources. As for ecological footprint, the highest amounts of compensation expense of the PLCG and WMA\&XJYCG appear in Nanchang and Wuhan, respectively. Generally, the cities that pay for ecological 
compensation are mostly concentrated in the center of each urban agglomeration with a high GDP. The ecological resources consumed by economic development exceed the regional ecological carrying capacity, and the ecological resources in other regions will be occupied and compensated.

\section{Acknowledgements}

This research was supported by the National Natural Science Foundation of China (Grant No. 41890824), Natural Science Foundation of Hebei Province (E2020202117), Science and Technology Project of Hebei Education Department (BJ2020019), Second Tibetan Plateau Scientific Expedition and Research Program (STEP) (2019QZKK1003), Science Foundation of Hebei Normal University (L2019B36),

Scientific and Technological Research Projects of Colleges and Universities in Hebei Province (QN2019054), and Beijing-Tianjin-Hebei collaborative innovation project of Tianjin Science and technology plan (19YFHBQY00050).

\section{Declarations}

Ethics approval and consent to participate -- Not applicable

Consent to Publish -- Not applicable

Authors Contributions -- Yizhong Chen: Methodology, Data curation, Writing original draft; Hongwei Lu: Methodology, Writing - Review \& Editing; Jing Li: Conceptualization, Project administration, Supervision; Youfeng Qiao: Data curation, Writing - review \& editing; Pengdong Yan: Visualization; Lixia Ren:Mapping; Jun 
Xia: Investigation

Competing interests -- The authors declare that they have no competing interests Availability of data and materials-- The datasets used and/or analyzed during the current study are available from the corresponding author on reasonable request.

Funding -- This research was supported by the National Natural Science Foundation of China (Grant No. 41890824), Natural Science Foundation of Hebei Province (E2020202117), Science and Technology Project of Hebei Education Department (BJ2020019), Second Tibetan Plateau Scientific Expedition and Research Program (STEP) (2019QZKK1003), Science Foundation of Hebei Normal University (L2019B36), Scientific and Technological Research Projects of Colleges and Universities in Hebei Province (QN2019054), and Beijing-Tianjin-Hebei collaborative innovation project of Tianjin Science and technology plan (19YFHBQY00050).

\section{References}

Araujo, M., Ometto, J., Filho, S. R., et al. (2019). The socio-ecological Nexus+ approach used by the Brazilian Research Network on Global Climate Change. Current Opinion in Environmental Sustainability, 39, 62-70. https://doi.org/10.1016/j.cosust.2019.08.005.

Asefa, T., Clayton, J., Adams, A., \& Anderson, D. (2014). Performance evaluation of a water resources system under varying climatic conditions: reliability, resilience, vulnerability and beyond. Journal of Hydrology, 508, 53-65. 
638

639

640

641

642

643

644

645

646

647

648

649

650

651

652

653

654

655

656

657

658

Chen, J. D., Wu, Y. Y., Wen, J., et al. (2016). Regional differences in China's fossil energy consumption: an analysis for the period 1997-2013. Journal of Cleaner Production, 142(2), 578-588.

https://doi.org/10.1016/j.jclepro.2016.05.135.

Dabkienė, V., Baležentis, T., \& Štreimikienè, D. (2020). Calculation of the carbon footprint for family farms using the Farm Accountancy Data Network: A case from Lithuania. Journal of Cleaner Production, 262, 121509. https://doi.org/10.1016/j.jclepro.2020.121509.

Dai, C., Qin, X. S., Chen, Y., et al. (2018). Dealing with equality and benefit for water allocation in a lake watershed: A Gini-coefficient based stochastic optimization approach. Journal of Hydrology, 561, 322-334.

https://doi.org/10.1016/j.jhydrol.2018.04.012.

Druckman, A., \& Jackson, T. (2008). Measuring resource inequalities: The concepts and methodology for an area-based Gini coefficient. Ecological Economics, 65, $242-252$.

https://doi.org/10.1016/j.ecolecon.2007.12.013.

Eliazar, I., \& Cohen, M. H. (2014). On social inequality: Analyzing the rich-poor disparity. Physica A: Statistical Mechanics and its Applications, 401, 148-158. https://doi.org/10.1016/j.physa.2014.01.033.

Fan, M., \& Chen, L. (2019). Spatial characteristics of land uses and ecological compensations based on payment for ecosystem services model from 2000 to 

https://doi.org/10.1016/j.ecoinf.2019.01.001.

661 Fang, K. (2015). Assessing the natural capital use of eleven nations: An application of a revised three-dimensional model of ecological footprint. Acta Ecologica Sinica, http://dx.doi.org/10.5846/stxb201308022011.

Fang, K., Heijungs, R., \& Snoo, G. R. D. (2014). Theoretical exploration for the combination of the ecological, energy, carbon, and water footprints: Overview of a footprint family. Ecological Indicators, 36, 508-518. https://doi.org/10.1016/j.ecolind.2013.08.017. https://doi.org/10.1016/j.envsci.2019.07.001.

Figueras, J. T., \& Duro, J. A. (2015). The building blocks of international ecological footprint inequality: a regression-based decomposition. Ecological Economics, $118,30-39$

\section{https://doi.org/10.1016/j.ecolecon.2015.07.014.}

Galli, A., Weinzettel, J., Cranston, G., et al. (2013). A Footprint Family extended MRIO model to support Europe's transition to a One Planet Economy. Science of The Total Environment, 461-462, 813-818. https://doi.org/10.1016/j.scitotenv.2012.11.071. 
681

682

683

684

685

686

687

688

689

690

691

692

693

694

695

696

697

698

699

700

701

702

Gao, X., Shen, J. Q., He, W. J., et al. (2019). An evolutionary game analysis of governments' decision-making behaviors and factors influencing watershed ecological compensation in China. Journal of Environmental Management, 251, 109592.

\section{https://doi.org/10.1016/j.jenvman.2019.109592.}

Giljum, S., Behrens, A., Hinterberger, F., et al. (2008). Modelling scenarios towards a sustainable use of natural resources in Europe. Environmental Science \& Policy, 11, 204-216.

https://doi.org/10.1016/j.envsci.2007.07.005.

He, Q. S., Zeng, C., Xie, P., et al. (2018). An assessment of forest biomass carbon storage and ecological compensation based on surface area: A case study of Hubei Province, China. Ecological Indicators, 90, 392-400. https://doi.org/10.1016/j.ecolind.2018.03.030.

Jiang, K., Merrill, R., You, D. M., et al. (2019). Optimal control for transboundary pollution under ecological compensation: A stochastic differential game approach. Journal of Cleaner Production, 241, 118391. https://doi.org/10.1016/j.jclepro.2019.118391.

Kaczan, D., Swallow, B. M., \& Adamowicz, W. L. (2013). Designing a payments for ecosystem services (PES) program to reduce deforestation in Tanzania: an assessment of payment approaches. Ecological Economics, 95, 20-30. https://doi.org/10.1016/j.ecolecon.2013.07.011.

Kinzig, A. P., Perrings, C., Chapin, F. S., et al. (2011). Paying for ecosystem 
services-promise or peril. Science, 334, 603-604. https://doi.org/10.1126/science.1210297.

705

Kissinger, M., \& Dickler, S. (2016). Interregional bio-physical connections-A 'footprint family' analysis of Israel's beef supply system. Ecological Indicators, 69, 882-891. https://doi.org/10.1016/j.ecolind.2016.05.024.

Kong, Y. C., Zhao, T., Yuan, R., et al. (2019). Allocation of carbon emission quotas in Chinese provinces based on equality and efficiency principles. Journal of Cleaner Production, 211, 222-232. https://doi.org/10.1016/j.jclepro.2018.11.178.

Li, M., Fu, Q., Singh, V. P., et al. (2020). Sustainable management of land, water, and fertilizer for rice production considering footprint family assessment in a random environment. Journal of Cleaner Production, 258, 120785. https://doi.org/10.1016/j.jclepro.2020.120785.

Lu, H. W., Kang, Y., Liu, L., et al. (2019). Comprehensive groundwater safety assessment under potential shale gas contamination based on integrated analysis of reliability-resilience-vulnerability and gas migration index. Journal of Hydrology, 578, 124072, https://doi.org/10.1016/j.jhydrol.2019.124072

Shu, H., \& Xiong, P. P. (2018). The Gini coefficient structure and its application for the evaluation of regional balance development in China. Journal of Cleaner Production, 199, 668-686.

https://doi.org/10.1016/j.jclepro.2018.07.224. 
Shulla, K., Filho, W. L., Sommer, J. H., et al. (2020). Channels of collaboration for citizen science and the sustainable development goals. Journal of Cleaner Production, 264, 121735. https://doi.org/10.1016/j.jclepro.2020.121735.

Song, B., Zhang, Y., Zhang, L. X., et al (2018). A top-down framework for cross-regional payments for ecosystem services. Journal of Cleaner Production, $182,238-245$.

https://doi.org/10.1016/j.jclepro.2018.01.203.

Stoeglehner, G., \& Narodoslawsky, M. (2008). Implementing ecological footprinting in decision-making processes. Land Use Policy, 25, 421-431. https://doi.org/10.1016/j.landusepol.2007.10.002.

Teng, F., He, J. K., Pan, X. Z., et al. (2011). Metric of carbon equity: carbon Gini index based on historical cumulative emission per capita. Advances in Climate Change Research, 2(3), 134-140. https://doi.org/10.3724/SP.J.1248.2011.00134.

Vanham, D., Leip, A., Galli, A., et al. (2019). Environmental footprint family to address local to planetary sustainability and deliver on the SDGs. Science of The Total Environment, 693, 133642. https://doi.org/10.1016/j.scitotenv.2019.133642.

Wang, J., Zhai, T. L., Lin, Y. F., et al. (2018). Spatial imbalance and changes in supply and demand of ecosystem services in China. Science of The Total Environment, $657,781-791$. 
Wang, W. X., Wang, W. J., Xie, P. C., et al. (2020). Spatial and temporal disparities of carbon emissions and interregional carbon compensation in major function-oriented zones: a case study of Guangdong province. Journal of Cleaner Production, 245, 118873.

\section{https://doi.org/10.1016/j.jclepro.2019.118873.}

Wang, Y., \& Wall, G. (2007). Administrative arrangements and displacement compensation in top-down tourism planning-A case from Hainan Province, China. Tourism Management, 28(1), 70-82. https://doi.org/10.1016/j.tourman.2004.09.007.

White, T. J. (2007). Sharing resources: the global distribution of the ecological footprint. Ecological Economics, 64, 402-410. https://doi.org/10.1016/j.ecolecon.2007.07.024.

Xue, J. J., Shen, L., Peng, B. X., et al. (2014). The economic and environmental performance of regional energy consumption: An empirical study on 14 major energy output and input provinces in China. Acta Geographica Sinica, 69, $1414-1424$.

\section{https://doi.org/10.11821/dlxb201410002.}

Yang, Y., \& Fan, M. D. (2019). Analysis of the spatial-temporal differences and fairness of the regional energy ecological footprint of the Silk Road Economic Belt (China Section). Journal of Cleaner Production, 215, 1246-1261. https://doi.org/10.1016/j.jclepro.2019.01.170. 
Yang, Y., Yao, C. X., \& Xu, D. L. (2020). Ecological compensation standards of national scenic spots in western China: A case study of Taibai Mountain. Tourism Management, 76, 103950. https://doi.org/10.1016/j.tourman.2019.103950.

Yu, B., Xu, L. Y., \& Yang, Z. F. (2016). Ecological compensation for inundated habitats in hydropower developments based on carbon stock balance. Journal of Cleaner Production, 114, 334-342. https://doi.org/10.1016/j.jclepro.2015.07.071.

\section{List of Figure Captions}

Figure 1. The location and land use of TOCC in China.

Figure 2. Spatial distribution of per unit of GDP and population in the TOCC across Yangtze River Economic Belt.

Figure 3. The precipitation and land-use types in the TOCC.

Figure 4. Variations in water-carbon-ecological footprints of different city groups.

Figure 5. Solutions of water footprint in different urban agglomerations.

Figure 6. Spatial-temporal dynamic variations of water carrying capacity across the TOCC.

Figure 7. Solutions of carbon footprint in different urban agglomerations.

Figure 8. Spatial-temporal dynamic variations of carbon footprint and carbon carrying capacity across the TOCC.

Figure 9. Solutions of ecological footprint in different urban agglomerations.

Figure 10. Spatial-temporal dynamic variations of ecological footprint in the TOCC.

Figure 11. The kernel distribution map of water-carbon-ecological footprints in different urban 
791 Figure 12. Variations of population, water, and GDP Gini coefficients from perspective of different 792 footprints across the TOCC.

793 Figure 13. Lorenz curve of the economic contribution, population, and water resources of the TOCC.

795 Figure 14. Variations in the average service consumption values of carbon and water resources in different urban agglomerations.

797 Figure 15. Compensation strategies in different urban agglomerations from the perspective of water-carbon-ecological footprints.

List of Table Captions

801 Table 1. Special cities identified with letters and numbers in the TOCC.

802 Table 2. Footprint index evaluation system.

803 Table 3. Some average Socio-economic data in different urban agglomerations. 


\section{Figures}

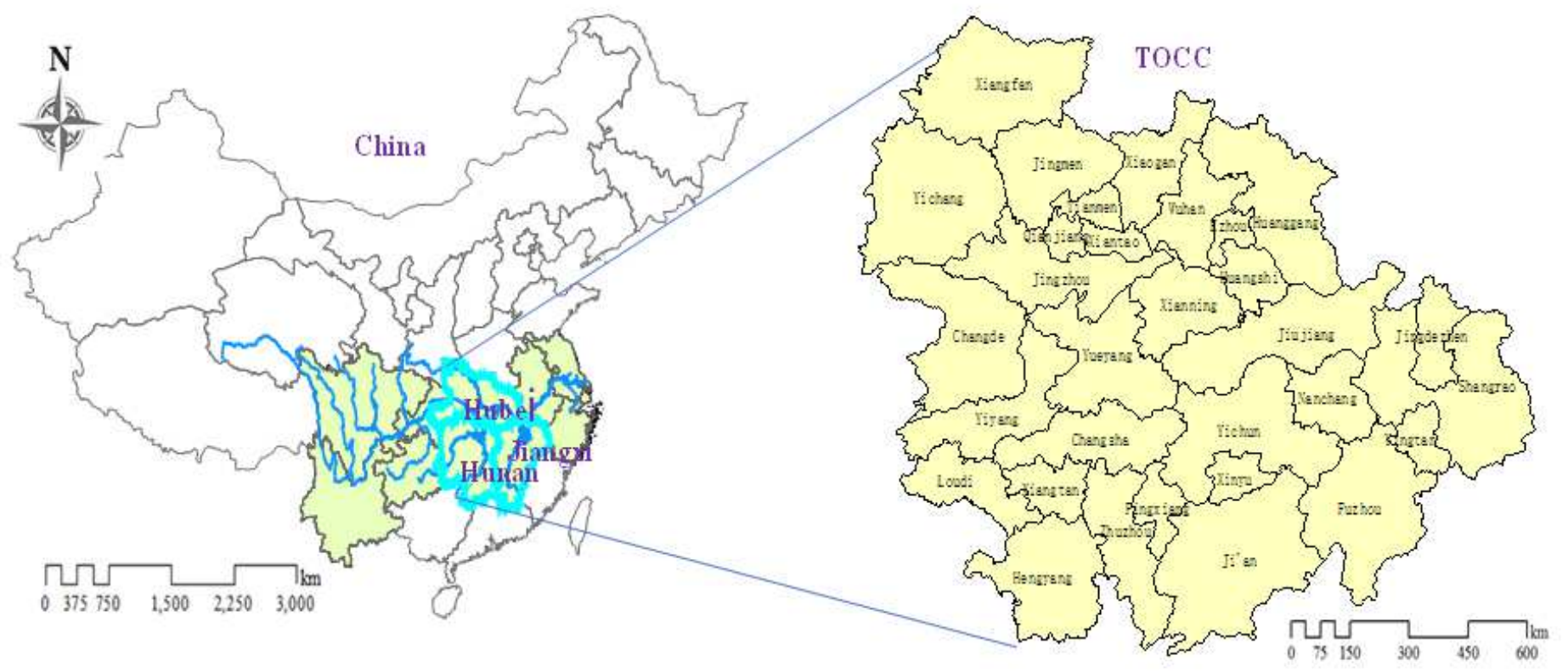

\section{Figure 1}

The location and land use of TOCC in China. Note: The designations employed and the presentation of the material on this map do not imply the expression of any opinion whatsoever on the part of Research Square concerning the legal status of any country, territory, city or area or of its authorities, or concerning the delimitation of its frontiers or boundaries. This map has been provided by the authors.
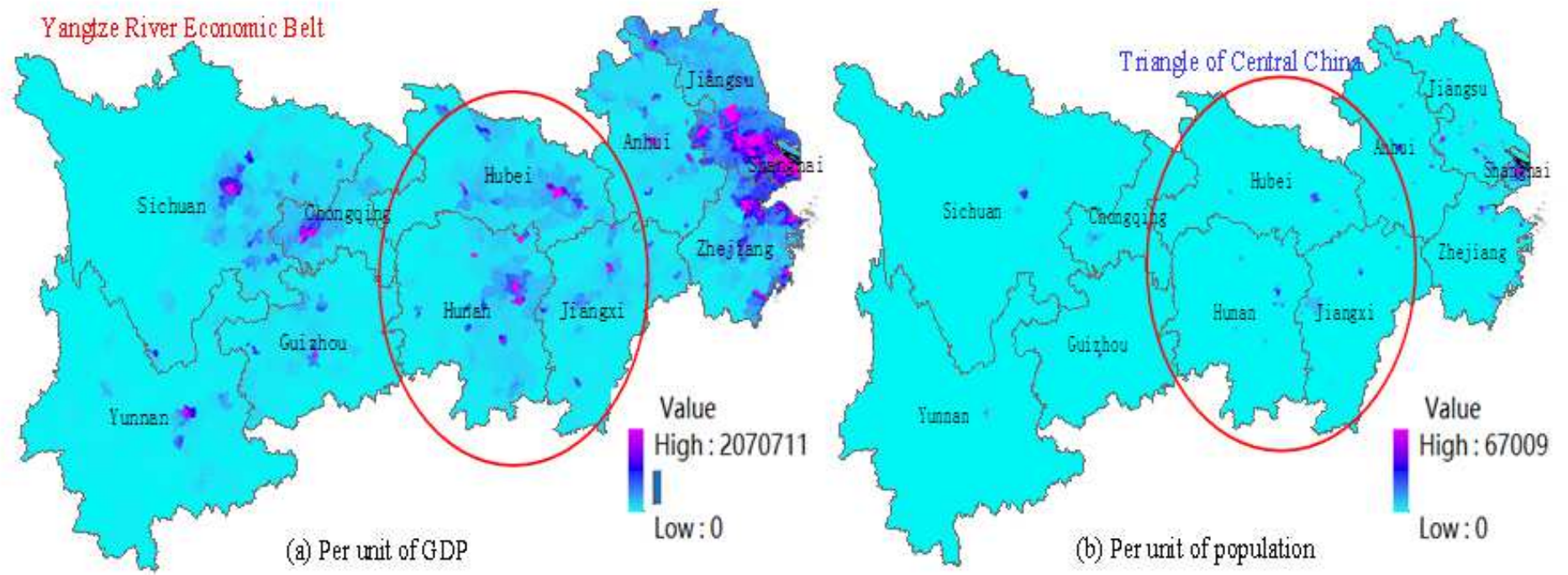

Figure 2

Spatial distribution of per unit of GDP and population in the TOCC across Yangtze River Economic Belt. Note: The designations employed and the presentation of the material on this map do not imply the expression of any opinion whatsoever on the part of Research Square concerning the legal status of any 
country, territory, city or area or of its authorities, or concerning the delimitation of its frontiers or boundaries. This map has been provided by the authors.

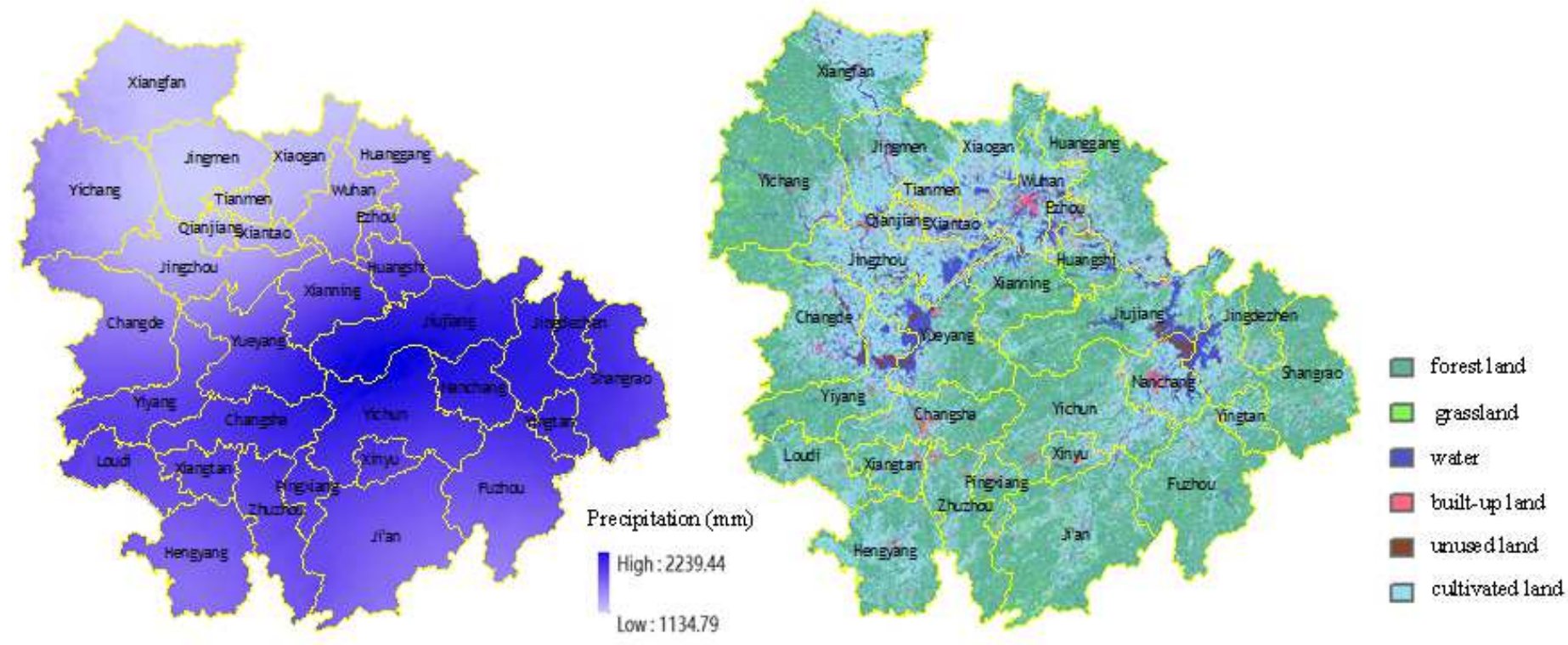

\section{Figure 3}

The precipitation and land-use types in the TOCC. Note: The designations employed and the presentation of the material on this map do not imply the expression of any opinion whatsoever on the part of Research Square concerning the legal status of any country, territory, city or area or of its authorities, or concerning the delimitation of its frontiers or boundaries. This map has been provided by the authors. 

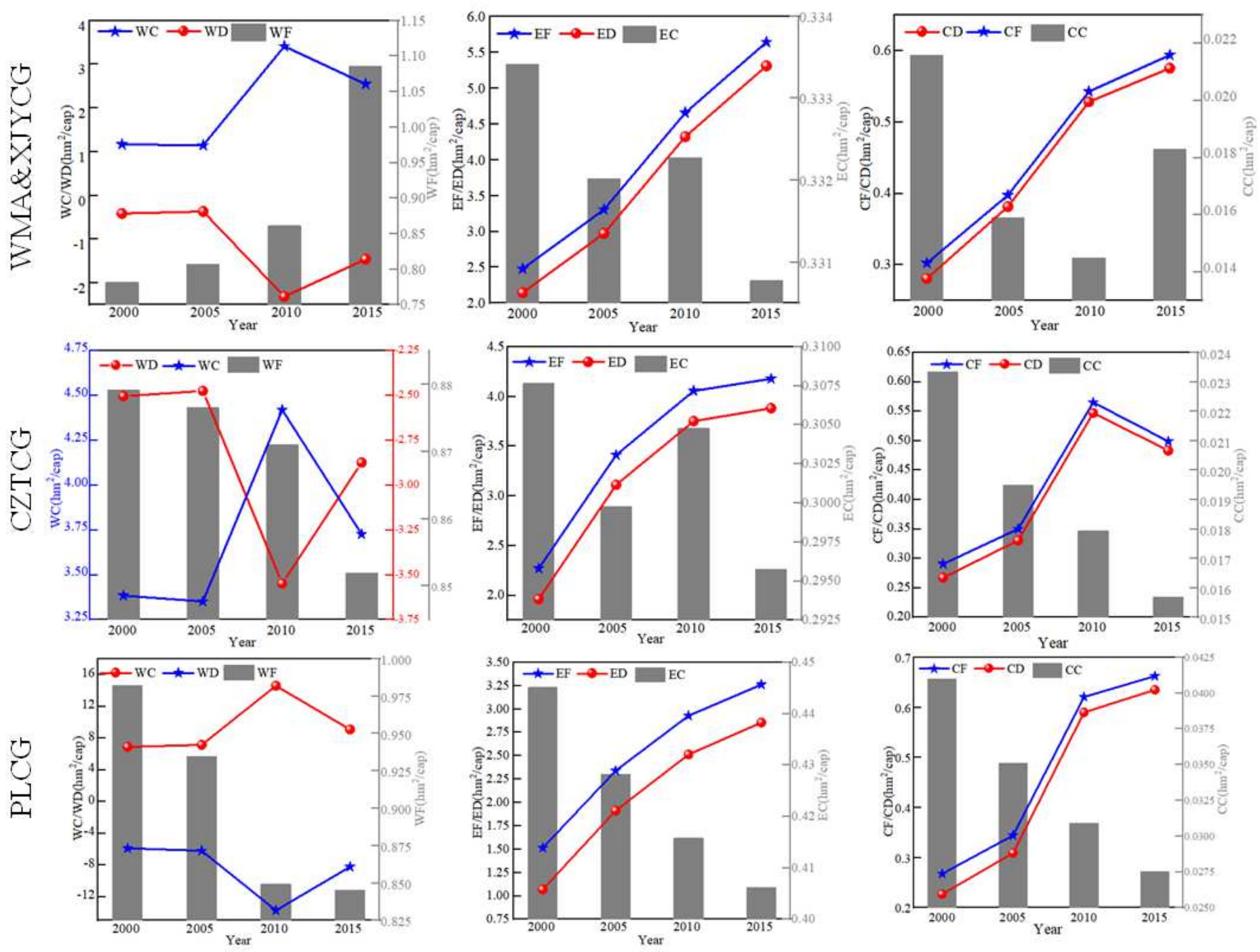

Figure 4

Variations in water-carbon-ecological footprints of different city groups. 


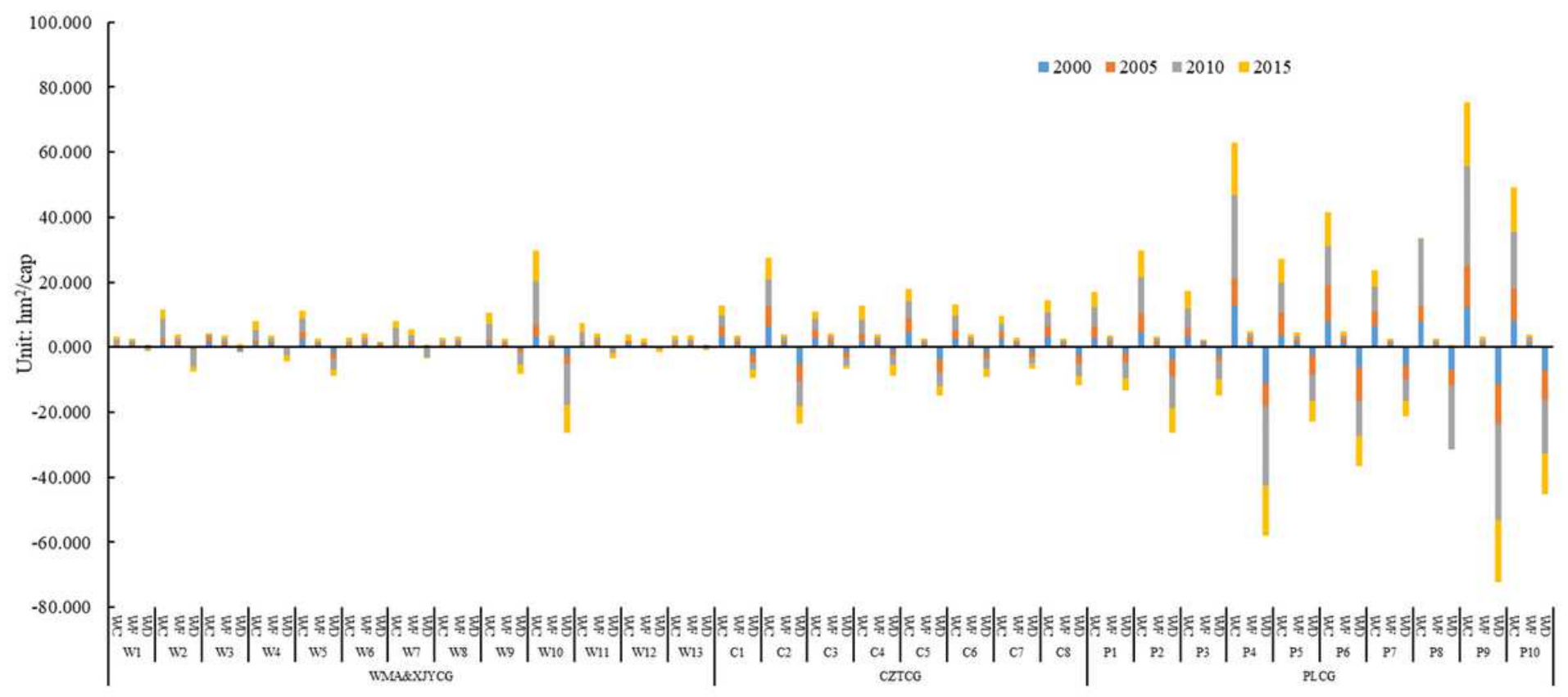

Figure 5

Solutions of water footprint in different urban agglomerations. 

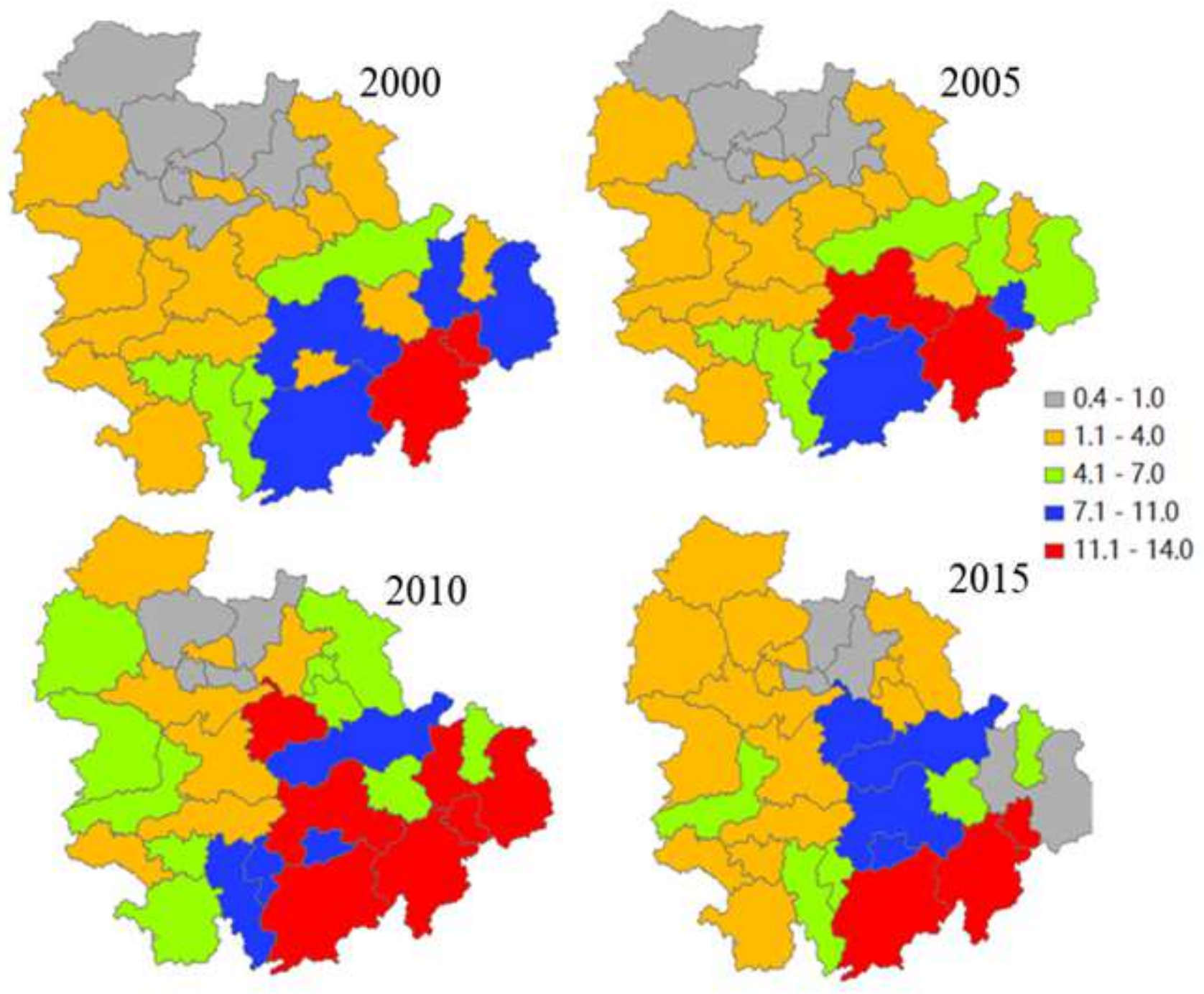

Figure 6

Spatial-temporal dynamic variations of water carrying capacity across the TOCC. Note: The designations employed and the presentation of the material on this map do not imply the expression of any opinion whatsoever on the part of Research Square concerning the legal status of any country, territory, city or area or of its authorities, or concerning the delimitation of its frontiers or boundaries. This map has been provided by the authors. 


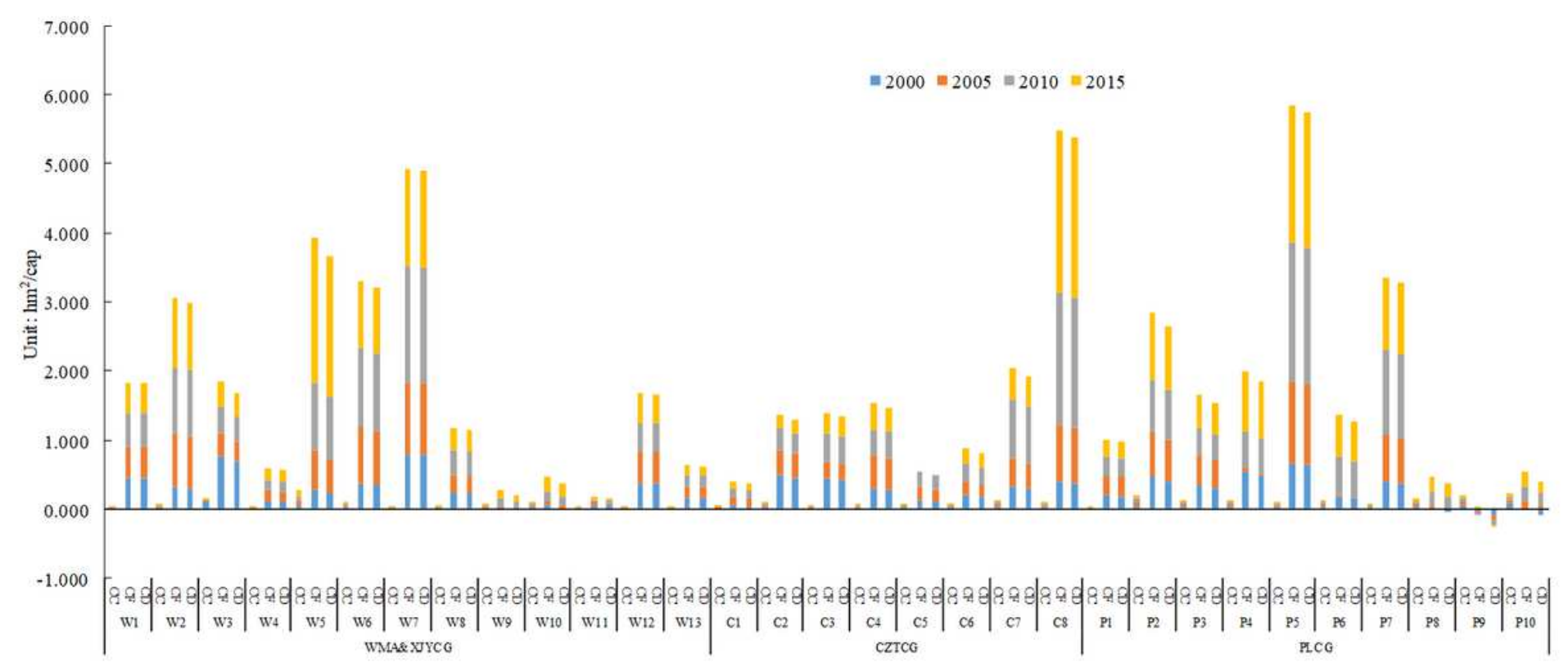

Figure 7

Solutions of carbon footprint in different urban agglomerations.
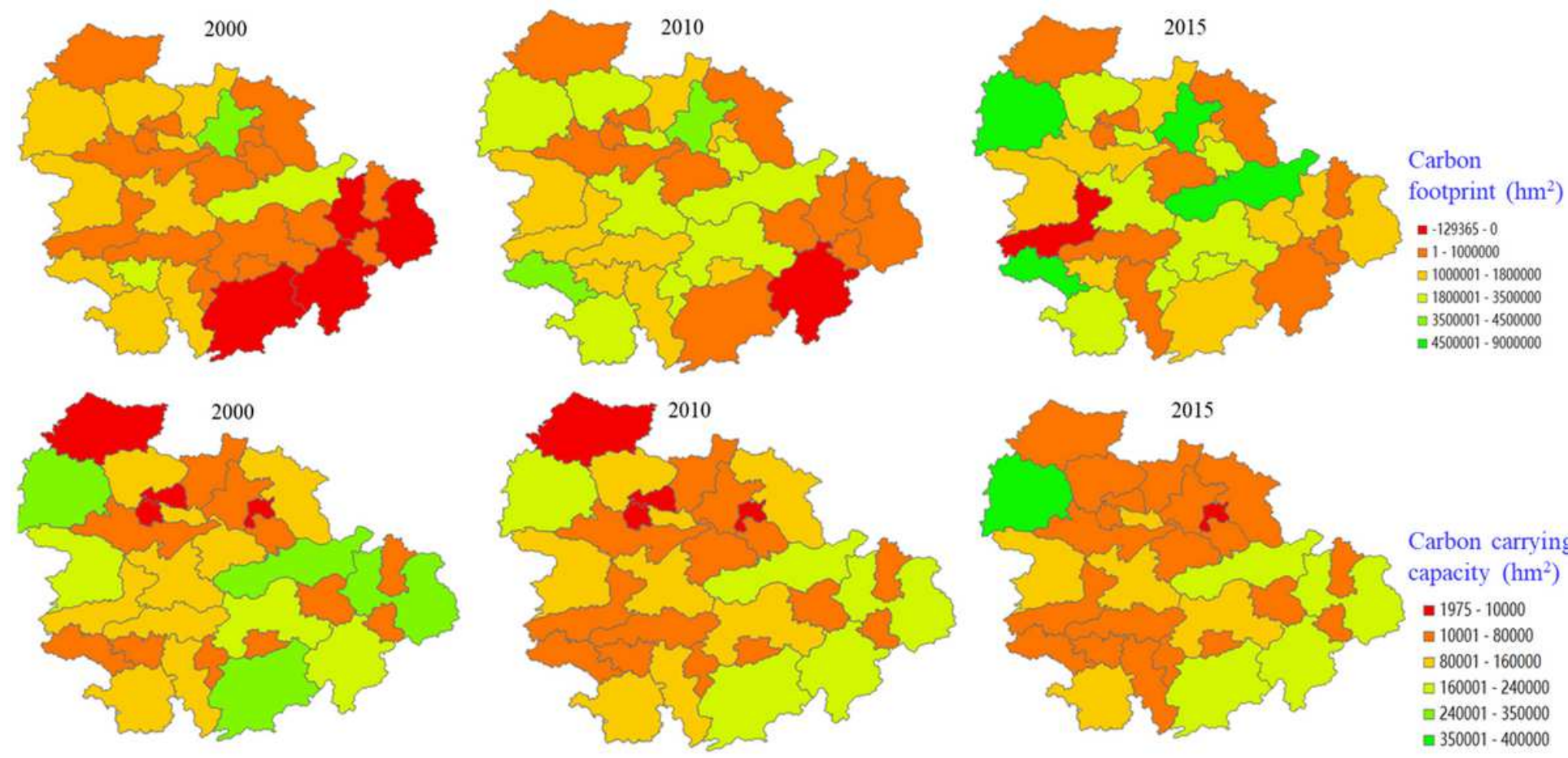

Carbon carrying capacity $\left(\mathrm{hm}^{2}\right)$ $=1975-10000$ $\pm 10001 \cdot 80000$ $\square 80001 \cdot 160000$ $\square 160001-240000$ $\square 240001 \cdot 350000$ $=350001-400000$

Figure 8

Spatial-temporal dynamic variations of carbon footprint and carbon carrying capacity across the TOCC. Note: The designations employed and the presentation of the material on this map do not imply the expression of any opinion whatsoever on the part of Research Square concerning the legal status of any country, territory, city or area or of its authorities, or concerning the delimitation of its frontiers or boundaries. This map has been provided by the authors. 


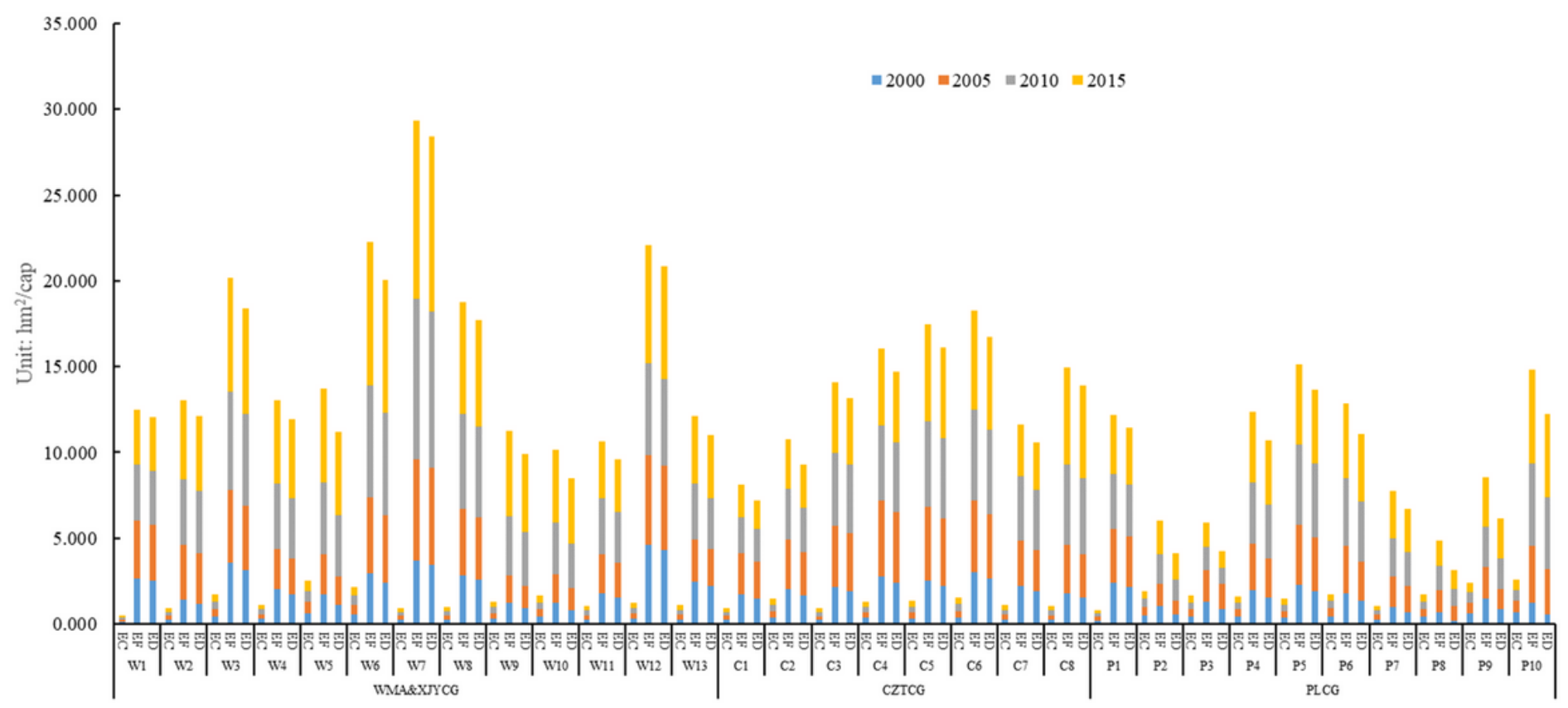

Figure 9

Solutions of ecological footprint in different urban agglomerations. 

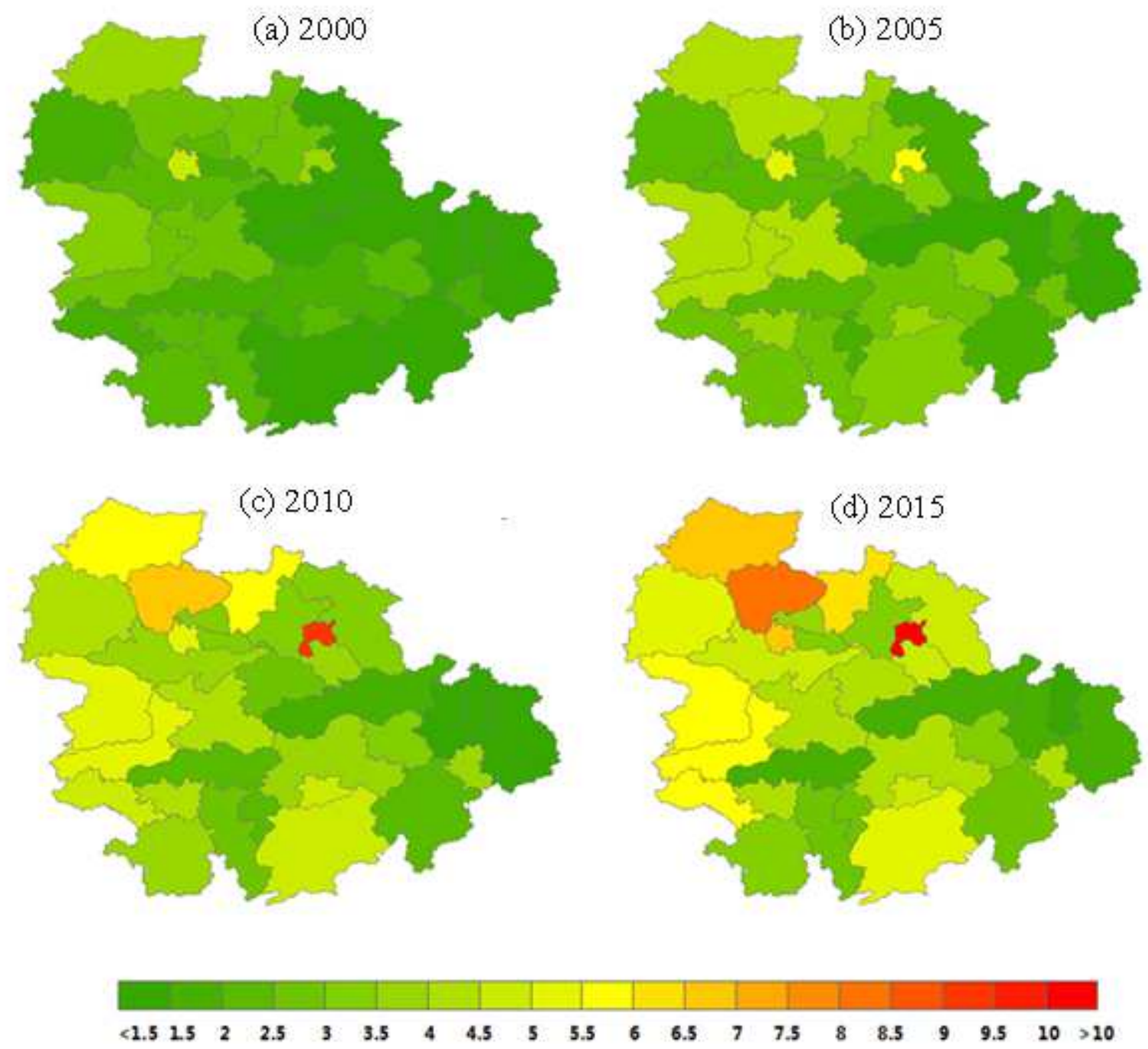

\section{Figure 10}

Spatial-temporal dynamic variations of ecological footprint in the TOCC. Note: The designations employed and the presentation of the material on this map do not imply the expression of any opinion whatsoever on the part of Research Square concerning the legal status of any country, territory, city or area or of its authorities, or concerning the delimitation of its frontiers or boundaries. This map has been provided by the authors. 

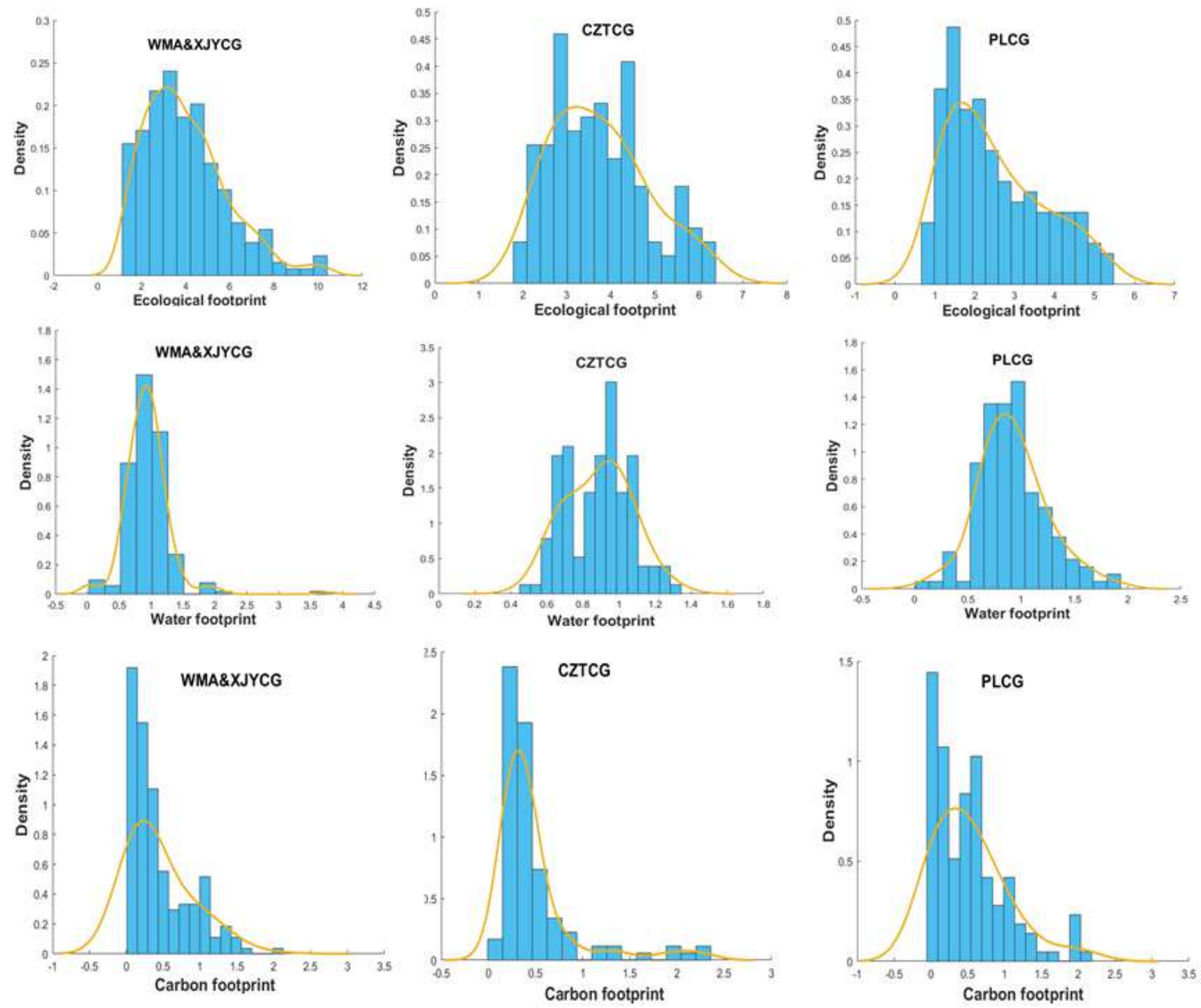

Figure 11

The kernel distribution map of water-carbon-ecological footprints in different urban agglomerations. 

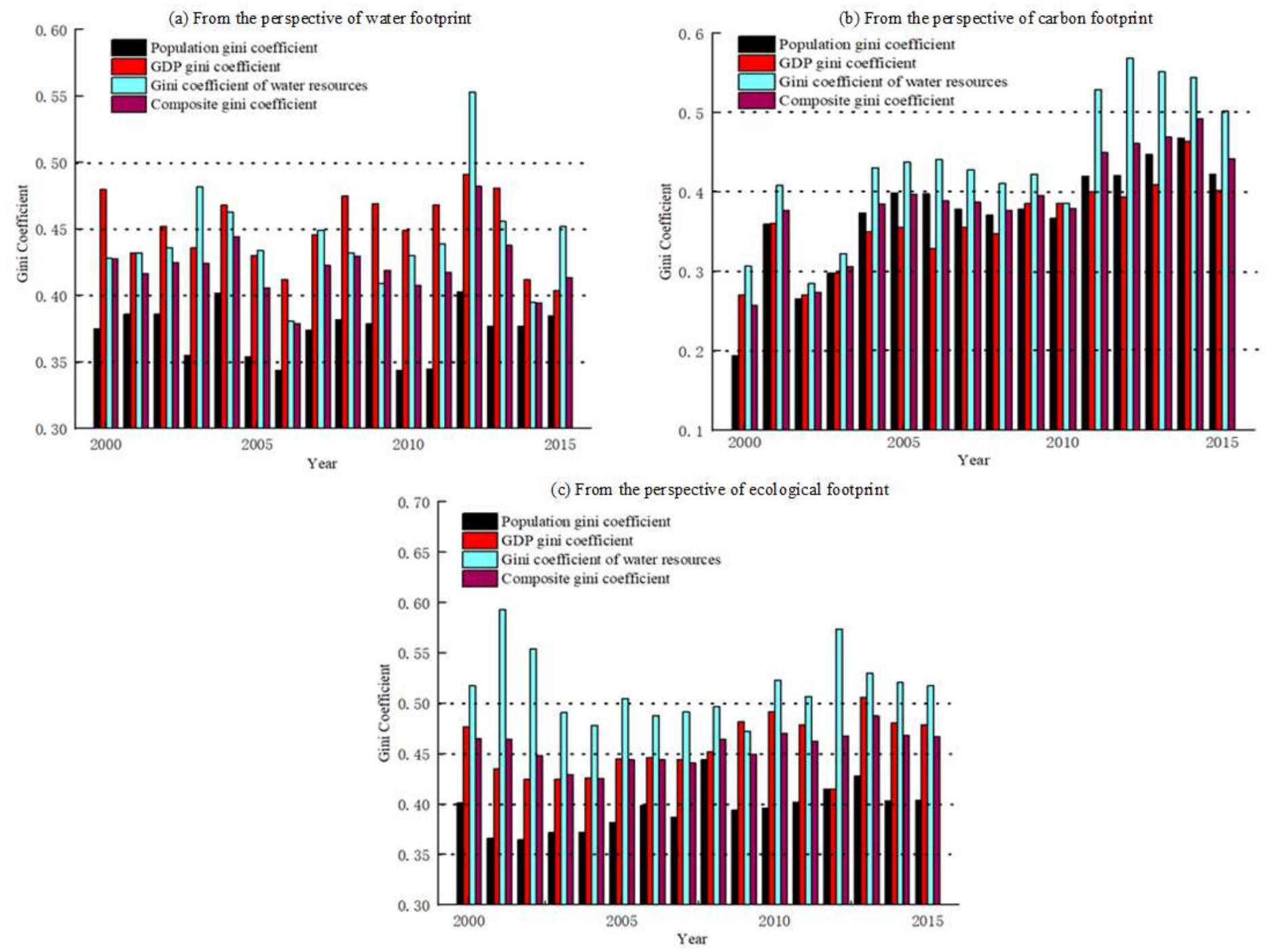

Figure 12

Variations of population, water, and GDP Gini coefficients from perspective of different footprints across the TOCC. 

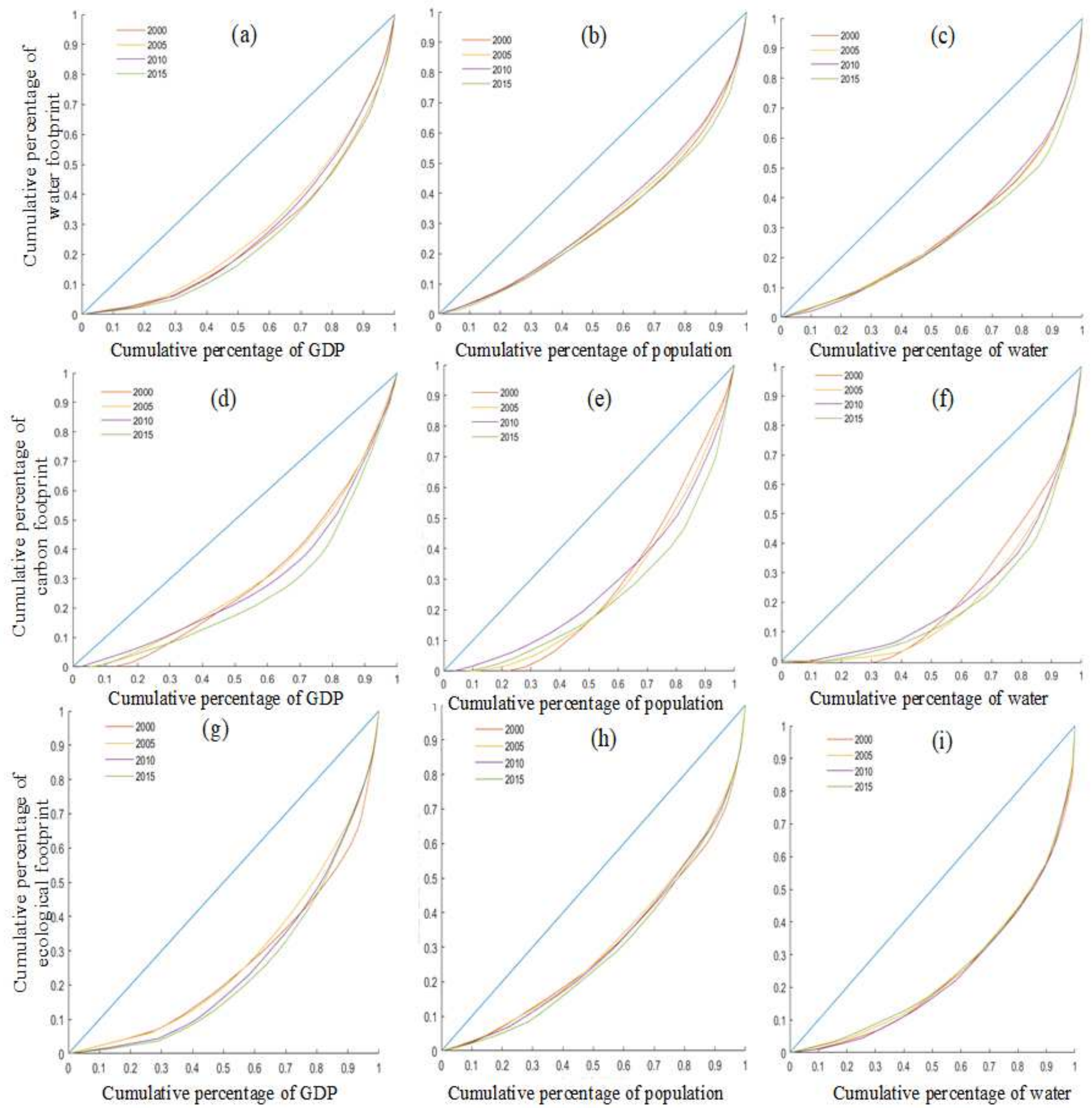

\section{Figure 13}

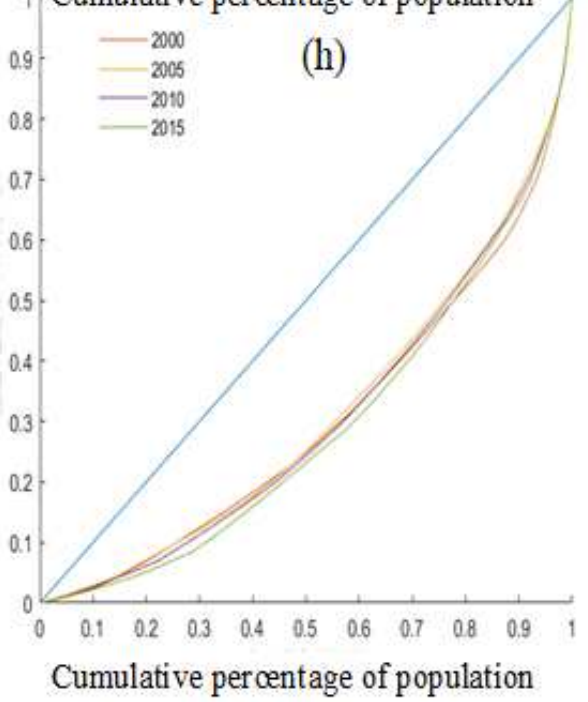

Lorenz curve of the economic contribution, population, and water resources of the TOCC. 


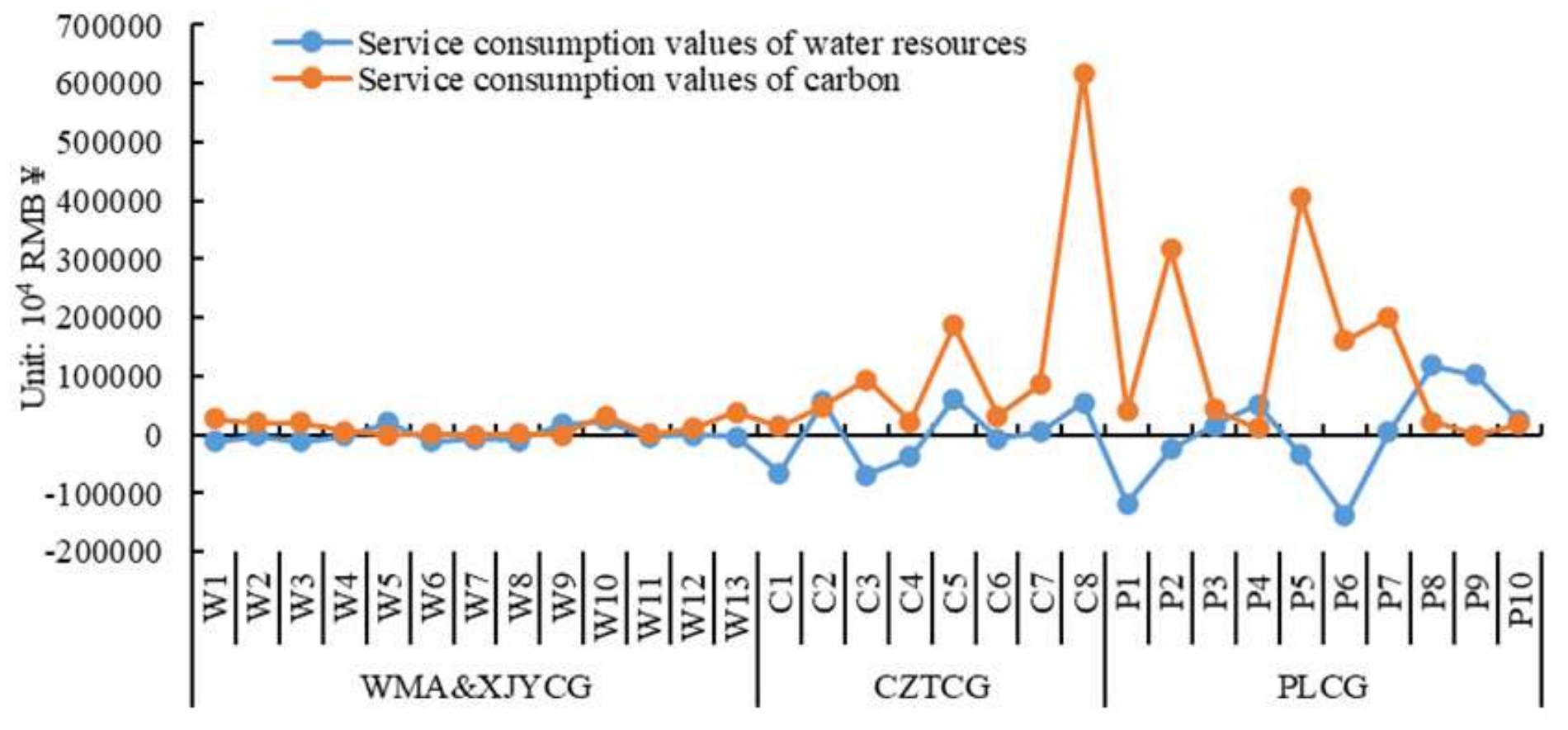

Figure 14

Variations in the average service consumption values of carbon and water resources in different urban agglomerations. 

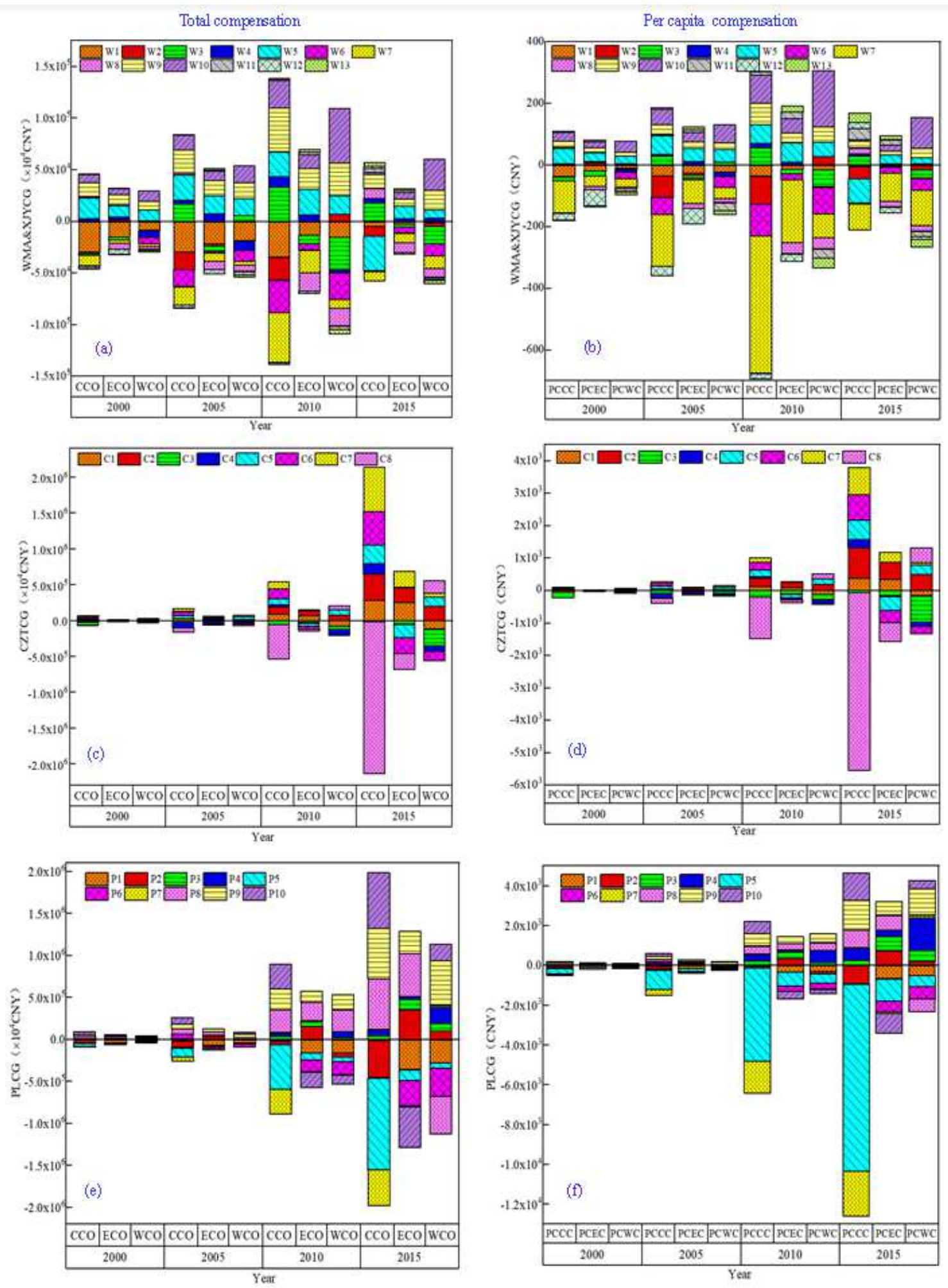

Figure 15

Compensation strategies in different urban agglomerations from the perspective of water-carbonecological footprints, where WCO, CCO, and ECO denote the total water, carbon, and ecological compensation strategies; PCWC, PCCC, and PCEC denote the per capita water, carbon, and ecological compensation strategies. 